\title{
Structure, Electrical and Optical Properties of ITO Thin Films and Their influence on Performance of CdS/CdTe Thin-Film Solar Cells
}

Moustafa Ahmed

King Abdulaziz University

Ahmed Bakry

King Abdulaziz University

Essam R Shaaban ( $\square$ esam_ramadan2008@yahoo.com )

Al-Azhar University https://orcid.org/0000-0003-4124-5744

Hamed Dalir

George Washington University

\section{Original Research}

Keywords: ITO thin films, Structural parameters, Electrical parameters, spectroscopic ellipsometry, energy gap, CdS/CdTe thin film

Posted Date: February 10th, 2021

DOI: https://doi.org/10.21203/rs.3.rs-204421/v1

License: (c) (i) This work is licensed under a Creative Commons Attribution 4.0 International License.

Read Full License

Version of Record: A version of this preprint was published at Journal of Materials Science: Materials in Electronics on April 1st, 2021. See the published version at https://doi.org/10.1007/s10854-021-05777-x. 


\title{
Structure, Electrical and Optical Properties of ITO Thin Films and Their influence on Performance of CdS/CdTe Thin-Film Solar Cells
}

\author{
${ }^{1}$ Moustafa Ahmed, ${ }^{1}$ Ahmed Bakry, ${ }^{2, *}$ Essam R. Shaaban, and ${ }^{3}$ Hamed Dalir \\ ${ }^{1}$ Department of Physics, Faculty of Science, King Abdulaziz University, 80203 Jeddah \\ 21589, Saudi Arabia \\ ${ }^{2}$ Physics Department, Faculty of Science, Al - Azhar University, P.O. 71452, Assiut, \\ Egypt \\ ${ }^{3,2}$ Department of Electrical and Computer Engineering, George Washington University, \\ 20052, Washington, D.C., USA \\ *Corresponding author: esam_ramadan2008@yahoo.com
}

\begin{abstract}
ITO was prepared by mixing gradient $\mathrm{In}_{2} \mathrm{O}_{3}$ and $\mathrm{SnO}_{2}$ powders using solid phase reaction manner. Using electron beam gun tool, ITO films with varied thicknesses were fabricated. The structure, electrical and optical parameters of the prepared films were studied. XRD patterns were used to establish the micro-structural parameters (lattice strain and crystallite size). The SEM shows improvement of grain size with the increase of the film thickness. The electrical parameters of ITO films were measured by means of the standard four-point probe method. It was found that when the film thickness increases from $75 \mathrm{~nm}$ to $375 \mathrm{~nm}$, the resistivity decreases to lower value of $1.65 \times 10^{-4} \Omega . \mathrm{cm}$ and slightly increases to $1.93 \times 10^{-4} \Omega . \mathrm{cm}$ at thickness of $375 \mathrm{~nm}$. The ITO films with lower electrical properties are appropriate for high-efficiency CdTe solar cells. In terms of spectral ellipsomeric, three optical layer models (adhesive layer of the substrate/B-spline layer of ITO film/surface roughness layer) were applied to estimate the film thickness with high accuracy. The absorption coefficient and energy gap were calculated from the transmission and reflection spectra in the strong absorption region. As the film thickness increases, the optical energy gap was found to increase from $3.56 \mathrm{eV}$ to $3.69 \mathrm{eV}$. In terms of Hall-effect measurements, both carrier concentration and hall mobility were determined. In addition, influences of ITO layers with various thicknesses on the performance of $\mathrm{CdS} / \mathrm{CdTe}$ solar cells were checked. When the ITO window layer thickness is $325 \mathrm{~nm}, \mathrm{~J}_{\mathrm{sc}}=17 \mathrm{~mA} / \mathrm{cm}^{2}, \mathrm{~V}_{\mathrm{oc}}=0.82 \mathrm{~V}$, and $\mathrm{FF}=57.4 \%$, the calculated highest power conversion efficiency (PCE) is $8.6 \%$.
\end{abstract}

Keywords: ITO thin films; Structural parameters; Electrical parameters; spectroscopic ellipsometry; energy gap; CdS/CdTe thin film. 


\section{1-Introduction}

Since long time ago, the expected use of transparent conductive oxide (TCO) films in various fields has been paying attention from the scientific community. Their fascinating characteristics and structural diversity have fully utilized in industry, space and daily life. Indium tin oxide is a transparent conductive oxide Due to its good sticking to the substrate, chemical instability and excellent photo-chemical properties, it has excellent performance and excellent applications. Its properties are the result of its n-type highly disintegrates semiconductor behavior and its broad band gap in the range of $3.5 \mathrm{eV}$ to 4.3 $\mathrm{eV}$ after miniaturization to nanoscale, which affects its structure, morphology, electrical and optical properties [1, 2]. ITO is familiar negative type of oxides. Now, tin is a cationic dopant in the indium oxide $\left(\operatorname{In}_{2} \mathrm{O}_{3}\right)$ lattice and acts as a substitute for interstitial oxygen bonding at the indium sites. Due to its high transmission, broad band gap (>3.5 eV) and electrical conductivity, ITO has been extensively functional in various optoelectronic tools and devices such as solar cells [1], liquid crystal [2] and gas sensors [3]. The ITO thin films are commonly fabricated by employing different techniques such

as magnetron sputtering [4-8], sol-gel process [9-11], thermal evaporation [12], pulsed laser deposition [13,14], chemical vapor deposition [15,16], spray pyrolysis [17-22] and nebulizer spray pyrolysis (NSP) [23]. In addition, ITO reveals interesting and technologically significance as an essential part in solar cells, energy efficient buildings, window coatings, and flat panel displays [24]. The optical, electrical and structure properties of ITO films such as structure, morphology, energy gap, and the nature of the impurities present are strongly govern by the preparation and growth conditions [25-27]. The target of the present work divided into six folds. The first is to study the effects of film thickness on the micro structural parameters (crystallize size and lattice strain) and electrical resistivity of ITO window layer. The second is calculation of film thickness with high precision in terms of spectroscopic ellipsometry. The third is using Van der Pauw method with Hall effect measurement system, the electrical parameters of the ITO film were is measured. The forth is studying the film thickness effect on optical properties via measuring $T(\lambda)$ and $R(\lambda)$ of ITO window layer. The fifth is checking the impact of ITO layers with a variety of thicknesses on the performance of CdS/CdTe solar cells. The sixth is the interpretation on the change in optical parameters and the 
performance of $\mathrm{CdS} / \mathrm{CdTe}$ solar cells in terms of microstructural parameters and electrical parameters.

\section{Experimental procedures}

Using the ball milling technology high purity $\mathrm{In}_{2} \mathrm{O}_{3}$ and $\mathrm{SnO}_{2}$ (99.99\%) powder (purchased from Aldrich ) were mixing in a mass ration of 75:25 in a ball milling for about one hour to fabricate ITO alloys. The mixed powder is then pressed into discshaped particles. The powder was compressed into pellets by uniaxial compression (20 $\mathrm{MPa}$ ), and then pressed at $210 \mathrm{MPa}$. Then the pellets were sintered at $1200{ }^{\circ} \mathrm{C}$ at a heating rate of $20{ }^{\circ} \mathrm{C} / \mathrm{min}$ in a 2-cap ambient atmosphere, and then cooled to space temperature at a rate of $20{ }^{\circ} \mathrm{C} / \mathrm{min}$. Such ITO particles are used as the initial material (after gridding), and the electron beam gun (Denton Vacuum DV 502 A) was used to deposit the powdered sample presence inside the quartz glass crucible at a pressure of about $10^{-6} \mathrm{~Pa}$ onto clean the glass substrate. FTM6 thickness monitor was used to monitor both the film thickness and rate of deposition. Through the fabrication process, the temperature of substrates was at temperature $100{ }^{\circ} \mathrm{C}$ and the rate of deposition was at 2 $\mathrm{nm} / \mathrm{sec}$. X-ray diffraction (XRD) of powder (Philips diffraction 1710) was utlized to check the phase clarity and the structure of the ITO powder and films. Use energy dispersive X-ray spectroscopy (EDAX) connected with a scanning electron microscope, SEM (JEOL JSM-6360LA, Japan) for composition analysis that confirm the error of the indicator element unexceed $2.1 \%$. The electrical properties of ITO films with were measured by Van der Pauw method with a Hall effect measurement method (HMS-5000, ECOPIA). Resistivity, mobility, carrier type and carrier concentration are obtained on a 1 $\mathrm{cm}^{2}$ glass substrate. The dual-beam spectrophotometer (UV-Vis-NIR JASCO-670) is used to measure the transmission and reflection of the film. Keithley's 2400 supply meter system is used in the solar simulator 1.5 worldwide spectrums (AM1.5G) under standard test setting to determine the current density versus voltage $(\mathrm{J}-\mathrm{V})$ characteristics of solar cell equipment. More details about solar has been described in Shen et al. [28] 


\section{Results and discussion}

\subsection{Structural analysis}

Rietveld refining is a method used to characterize crystalline materials [29]. The XRD pattern of the ITO powder sample result is characterized by reflection (peak intensity) at convinced positions. The position, height and width of this reflection can be used to determine many aspect of the structure of the material. The Rietveld treatment utilizes the least squares method to treat the theoretical line contour until it matches the measured contour. Fig.1 illustrates the sample grinding of Rietveld powder to ITO. Fig. 2 shows the diffraction peaks of ITO films with different thicknesses in the XRD pattern belonging to the ITO (JCPDS data file: 39-1058-cubic), which is better oriented along the (222) plane. The main characteristics of these trends are the same, but only small differences are noticed during the peak duration. For the (222), (400), and (411) orientation planes, the diffraction angle $2 \theta$ is $30.27,35.17$, and 50.98 , respectively, and suitable sharp diffraction peaks are observed. Fig. 3 also shows that as the film thickness grows, the diffraction intensity of the (222) plane increases, and the increase in thickness significantly improves the crystallization efficiency of the deposited film.

The peak broadening is attributed to instrumental factors and structural factors $\mathrm{t}$ (that depend on lattice strain and crystal size). The crystal size $(D)$ and lattice strain $(e)$ are calculated by Scherrer and Wilson equations [30, 31] as follows:

$$
\begin{aligned}
& D=\frac{0.9 \lambda}{\beta \cos \theta} \\
& e=\frac{\beta}{4 \tan \theta}
\end{aligned}
$$

Where $\beta$ is the width of the peak, which is equal to the difference between the width of the film and the width of standard silicon.

$$
\beta=\sqrt{\beta_{o b s}^{2}-\beta_{\text {std }}^{2}} \text {. }
$$

Fig. 4 and Fig. 5 shows the two parameters ( $D$ and $e$ ) as the function of film thickness. It is practical that the average crystallite size rises with raising the film thickness but the lattice strain decreases. The observed micro-strain behavior may due to the reduce in 
crystallite size. Similarly, the reduce in lattice strain reflects the reduce in the concentration of lattice imperfection, which may be due to the drop off in width as the thickness increases.

Fig 6 displays the SEM of three different thickness (a) $d=75 \mathrm{~nm}$, (b) d = $225 \mathrm{~nm}$ and $\mathrm{d}=325 \mathrm{~nm}$ of ITO films. It can be clearly seen from this Figures 2 that as the film thickness increases the grain size of ITO increases. At the same time, the surface morphology of the ITO film becomes more compact and uniform, and as the thickness of Figure 2 increases, the crystal quality gradually improves. It should also be noted that the film is fully crystalline for higher thicknesses, which can lead to enhanced charge carrier transport and collection and further enhance device performance. Therefore, it can be concluded that the thickness $(325 \mathrm{~nm})$ of ITO film shows better crystal feature, which is also in good harmony with the earlier results of XRD. The SEM average grain size value is significantly larger than the grain size calculated by the XRD study, because the grain is composed of many grains [32].

\subsection{Electric properties}

The decrease in resistivity leads to a relatively high charge carrier density, which in turn causes mobility, which could be attributed to the relatively high crystal quality, larger grain size and excess cations (In or Sn); all lead to both an increase in charge carriers and a decrease in grain boundary scattering. That is, ITO films with lower electrical properties will be more appropriate for high-efficiency CdTe solar cells.

The electrical properties of ITO layer films with different thicknesses were measured by a standard four-point probe method. The necessary formula for sheet resistance measurement is: $R \mathrm{~s}=4.53 \cdot \mathrm{V} / \mathrm{I}[\Omega / \mathrm{sq}]$, where: $\mathrm{V}$ is the voltage in volts, $\mathrm{I}$ is the current in amperes, and the value 4.53 is the correction constant. If the film thickness is $d$, the relationship between resistivity $\rho$ (in ohm $\mathrm{cm}$ ) and $\mathrm{Rs}$ is given by $\mathrm{Rs}=\rho / \mathrm{d}$ [33].

The relationship between the resistivity of the ITO film and the film thickness is shown in Fig. 7. It can be seen from Fig. 7 that as the ITO film thickness increases from $75 \mathrm{~nm}$ to $375 \mathrm{~nm}$, the resistivity decreases from $29 \times 10^{-4} \Omega / \mathrm{cm}$ to $1.65 \times 10^{-4} \Omega / \mathrm{cm}$, respectively. The Hall Effect results are shown in Table 1 and Fig 7. The measurement results show that the ITO films are n-type. Fig. 7 shows the measured electrical 
parameters of prepared ITO thin films as a function of film thickness. It can be seen that the carriers concentration is increased and mobility is varies with increasing the film thickness. The optimal values of both the carrier concentration are the mobility at thickness $325 \mathrm{~nm}$. This results indicate that an extra of carrier concentration which leading to decrease of resistivity. The increase of mobility is related to reduction of grain boundary scattering due to the increase of crystallites size.

\subsection{Optical properties}

For ITO films of different thicknesses, a dual beam spectrophotometer can be used to obtain the measured values of optical transmittance $(T)$ and reflectance $(R)$ relative to wavelength. Fig. 8 shows the wavelength spectra of $T$ and $R$. The transmittance is found to be decreased with increasing the film thickness particularly in the NIR region. In the near-infrared region, due to the large number of free electrons in the film, the interaction between free electrons and incident light occurs. This interaction may cause the polarization of the light in the film, which causes a remarkable decreasing in the

transmission spectra, thereby affecting the dielectric constant. Transmittance is highly dependent on thickness of prepared thin films. But the reflectance spectra of the same set of films. It shows that for wavelengths above $1900 \mathrm{~nm}$, the reflectivity will increase slightly. However, this increase in reflectance does not coincide with the decrease in transmittance in the same area. Therefore, as the thickness of the near-infrared region increases, the decrease in transmittance is attributed to free carrier absorption, which is common in all transparent conductors with high carrier concentration [34].

The film thickness is calculated by the spectroscopic ellipsometry parameters $(\psi$ and $\Delta$ ), which are measured in the wavelength range of 380-880 $\mathrm{nm}$ using a rotating compensator instrument (J.A. Woollam, M-2000). All the details of this method have been clearly seen in references [35-37]. The data was acquired at a $70^{\circ}$ incident angle. According to the developed WVASE32 program, as shown in Figure 9, three optical layer models (Cauchy layer of substrate /B-spline layer of ITO film/surface roughness layer) are used to determine the film thickness with high accuracy. 
In a higher absorption region for both $T(\lambda)$ and $R(\lambda)$, the absorption coefficient, $\alpha$ can be derived from the following expression[38, 39]:

$$
\alpha=\frac{1}{d} \ln \left[\frac{(1-R)^{2}+\left[(1-R)^{4}+4 R^{2} T^{2}\right]^{1 / 2}}{2 T}\right]
$$

where $d$ is the thickness of the film. Fig. 10 shows the reliance of $\alpha(h v)$ on photon energy, $h v$ as a function of film thickness. Pure semiconducting compounds are known to have a sharp absorption edge [38, 39]. The edge of absorption was sharper and moved to higher wavelengths, as the film thickness rose from $75 \mathrm{~nm}$ to $325 \mathrm{~nm}$. It is known that the $\alpha$ value is described in the higher neighborhood of the fundamental absorption edge (higher $10^{4} \mathrm{~cm}^{-1}$ ), for allowed direct transition from valance band to conduction band. But the value of $\alpha$ at energy rang extended from 1 to $2 \mathrm{eV}$ represent a transparent visible region. The energy gap value is calculated using the following Tauc relation [40]

$$
\alpha(h v)=\frac{K\left(h v-E_{g}^{o p t}\right)^{m}}{h v}
$$

where $\mathrm{K}$ is a parameter independent of $h v$ for the individual transitions [35], $E_{g}^{o p t}$ is the optical energy gap, and $m$ is a number that identify the type of the transition. Various authors [41-43] recommended different $m$ values, such that $m=2$ for the majority amorphous semiconductors (indirect transition) and $\mathrm{m}=1 / 2$ for the majority of crystalline semiconductors (direct transition). At different annealing temperature of $\mathrm{Cu}$ doped CdTe film, the direct transition is valid. Fig 11 illustrates the best fit of $(\alpha h v)^{2} v s$. $h v$ for varies thickness. The direct optical band gap $E_{g}^{o p t}$ can be taken as the intercept of $(\alpha . h v)^{2}$ against. $(h v)$ at $(\alpha h v)^{2}=0$. The $E_{g}^{\text {opt }}$ resulting for each film is shown in Fig. 10 . The $E_{g}^{o p t}$ increase as the film thickness increases. The value of the optical band gap $E_{g}^{o p t}$ was found to vary from 3.56 in the film for $d=75 \mathrm{~nm}$ to $3.69 \mathrm{eV}$ for $\mathrm{d}=325 \mathrm{~nm}$. This increase was may attributed to reasons the first is a reduction in the resistivity of the films, implying an enhancement of the carrier density as in Fig. 7, and this change is well 
known as the Burstein-Moss shift [44] and the second is due to the increasing in crystallites size i.e increasing of the crystallinity of the film with increasing the thickness.

\subsection{Impact of thickness of ITO window layer in the performance CdS/CdTe solar cells}

The schematic diagram of the configuration of the $\mathrm{CdS} / \mathrm{CdTe}$ solar cell is shown in Fig. 11. Thus, the device configuration is a simple n-p heterojunction with an ohmic contact at the p-CdTe/metal interface. In order to show the influence of ITO layer thickness on the performance of CdS/CdTe solar cells, CdS/CdTe cells based on varies ITO window layer thicknesses were equipped. Figure 12 (a, b and c) shows the current density-voltage (J-V) characteristics of the CdS/CdTe cells (with the ITO layer thickness is $75 \mathrm{~nm}, 225 \mathrm{~nm}, 325 \mathrm{~nm}$ and $375 \mathrm{~nm}$ ) and the corresponding photovoltaic parameters are shown in these figures. Fig. 12 (c) was clarified that the highest power efficiency (PE) is $8.6 \%$ with $V_{\mathrm{oc}}=0.82 \mathrm{~V}, J_{\mathrm{sc}}=17 \mathrm{~mA} / \mathrm{cm}^{2}, \mathrm{FF}=57.4 \%$ at the ITO layer thickness is $325 \mathrm{~nm}$. We think that this development in the device performance may be associated to the high transmittance, carriers concentration and mobility values under this ITO layer thickness.

In addition, the $J_{\mathrm{sc}}$ of the cells with the ITO window layer of $75 \mathrm{~nm}, 225 \mathrm{~nm}$ and $375 \mathrm{~nm}$ is lower than the Jsc of the cell with the ITO window layer of $325 \mathrm{~nm}$. The cause for the elevated in $V_{\mathrm{oc}}$ and $J_{\mathrm{sc}}$ based on the $325 \mathrm{~nm}$ ITO layer may be due to the development of photoelectric characteristics, because due to the lowest value of reflectivity, higher value of carriers concentration and hall mobility, which causes a large number of photons are absorbed into the $\mathrm{CdS} / \mathrm{CdTe}$ solar cell, resulting in more absorption in the absorption layer. Photo-generated carriers and further enhanced $V_{\mathrm{oc}}$ and $J_{\text {sc. }}$ Additionally, the main reason for the highest $V_{\mathrm{oc}}$ and $J_{\mathrm{sc}}$ may be attributed to the first is an increasing in grain size thus improvement of cystallinity with the larger thickness and the second is due to smaller resistivity. The lower resistivity of $325 \mathrm{~nm}$ ITO layer can take part to the development of the FF of CdS/CdTe solar cells. Combining with the above analysis, it can be concluded that $325 \mathrm{~nm}$ ITO window layer is beneficial for the improvement of PEC for CdS/CdTe solar cells. Based on the above study, it can be accomplished that the $325 \mathrm{~nm}$ ITO window layer is useful to the development of the PE of CdS / CdTe solar cells. 
Such material characterization for light-matter interactions bears a high-relevance for photo conversion applications such as solar cells. In fact, recent work on windowintegrated PC concentrators [45,46] has shown to deliver both renewable power generation whilst allowing for spectral-tuning of the optical structure to allow for natural room lighting and reduced air conditioning load on a dwelling by designing photonic structures (e.g. high contrast gratings) to reflect the infrared spectrum (reducing heat load), yet transmitting the visible portion. Indeed, the in this study found interplay between material quality to solar cell performance can be extended, in principle, to high absorption atomically-flat van-der Waals materials such as those belonging to the class of transition metal dichalcogenides (TMD) for light emission [47] and light detection [48, 49]. In fact recent work points to some interesting scaling laws in photodetectors combining such emerging highly-absorptive materials with scaling-length-theory known from transistor short-channel devices, enabling a new class of high-gain-bandwidth product photodetectors [50].

Furthermore, controlling the ITO material properties during the deposition process is critical given plurality of control parameters of ITO such as activating the $\mathrm{Sb}$ dopants via annealing or adding/subtracting oxygen [51, 52]; both impact the complex optical index, and hence the transport properties such as the resistivity and mobility. Our material property findings for ITO in this study are indeed far-ranging beyond photoabsorption, but can further be used to electro-optic devices as well [53-56]. For instance, the optical index can be tuned electrostatically via chancing the free carrier concentration leading to electro-optic modulators, both for electro-absorption [57-59], but also used in interferometric schemes [60-62] to demonstrate high-performance modulators. This tunability of ITO thin films can be uniquely utilized also for 2 × 2 switches in integrated photonics [63], as electro-optic nonlinear activation function in photonic neural networks [64], or as a phase-shifter for optical phase array applications for LiDAR systems [65]. Interestingly, the unique properties of ITO have recently inspired applications for photonic and nano-optic analog computing schemes such as for solving partial differential equations [66].

\section{Conclusions}


The structural, morphological, electrical and optical properties of ITO films with various thicknesses were investigated. Besides, influences of the different ITO layer thicknesses on the properties of $\mathrm{CdS} / \mathrm{CdTe}$ solar cells were characterized. The film thickness was calculated using spectroscopic ellipsometry with high precision using three optical layer models (Cauchy layer of substrate /B-spline layer of ITO film/surface roughness layer). The results indicated that the crystallites size identified via XRD pattern and grain size determined by SEM were increased with raising the ITO film thickness. The resistivity decreased sharply from $29 \times 10^{-4} \Omega / \mathrm{cm}$ to $1.65 \times 10^{-4} \Omega / \mathrm{cm}$ with increasing ITO film thickness from $75 \mathrm{~nm}$ to $325 \mathrm{~nm}$. The transmittance spectra found to be decreased with increasing the film thickness particularly in NIR region due to the large number of free electrons in the film, the interaction between free electrons and incident light occurs. The optical band gap was calculated in terms of transmittance and reflection spectrum in the high region of the absorption. In terms of Tauc's relationship the possible transition of ITO films found to be allow direct transition with increasing of the band gap from 3.56 to $3.69 \mathrm{eV}$ with an increase of the film thickness from $75 \mathrm{~nm}$ to $325 \mathrm{~nm}$. The impacts of ITO layers with various thicknesses on the performance of CdS/CdTe solar cells were also studied. The highest power conversion efficiency (PCE) is $8.6 \%$ with $\mathrm{V}_{\mathrm{oc}}$ $=0.82 \mathrm{~V}, \mathrm{~J}_{\mathrm{sc}}=17 \mathrm{~mA} / \mathrm{cm}^{2}, \mathrm{FF}=57.4 \%$ when the ITO window layer thickness is 325 $\mathrm{nm}$.

\section{Acknowledgments}

This project was funded by the Deanship of Scientific Research (DSR) at King Abdulaziz University, Jeddah, under grant no. (RG-38-130-41). The authors, therefore, acknowledge with thanks DSR technical and financial support.

\section{References}


[1] H.R. Fallah, M. Ghasemi, and A. Hassanzadeh, Physica E 39, 69 (2007).

[2] M.J. Alam and D.C. Cameron, Thin Solid Films 377, 455 (2000).

[3] G. Neri, A. Bonavita, G. Micali, G. Rizzo, E. Callone and G. Carturan, Sens. Actuators B, 132, 224-233 (2008).

[4] J.H. Park, C. Buurma, S. Sivananthan, R. Kodama, W. Gao and T.A. Gessert, Appl. Surf. Sci., 307, 388-392 (2014).

[5] K.-S. Tseng and Y.-L. Lo, Appl. Surf. Sci., 285P, 157-166 (2013).

[6] K.C. Heo, Y.k. Sohn and J.S. Gwag, Ceram. Int., 41, 617-621 (2015).

[7] Y.S. Jung, D.W. Lee and D.Y. Jeon, Appl. Surf. Sci., 221, 136-142 (2004).

[8] A. Klo Eppel, W. Kriegseis, B.K. Meyer, A. Scharmann, C. Daube, J. Stollenwerk and J. Trube, Thin Solid Films, 365, 139-146 (2000).

[9] Y. Wang, J. Liu, X. Wu and B. Yang, Appl. Surf. Sci., 308, 341-346 (2014).

[10] M.T. Kesim and C. Durucan, Thin Solid Films, 545, 56-63 (2013).

[11] L. Korosi, S. Korosi and I. Dekany, Thin Solid Films, 519, 3113-3118 (2011).

[12] K.-Y. Pan, L.-D. Lin, L.-W. Chang and H.C. Shih, Appl. Surf. Sci., 273, 12-18 (2013).

[13] J.B. Choi, J.H. Kim, K.A. Jeon and S.Y. Lee, Mater. Sci. Eng. B, 102, 376-379 (2003).

[14] J.M. Dekkers, G. Rijnders and D.H.A. Blank, Appl. Phys. Lett., 88, 151908 (2006).

[15] Y.C. Park, Y.S. Kim, H.K. Seo, S.G. Ansari and H.S. Shin, Surf. Coat. Technol., $161,62-69$ (2002).

[16] Y.S. Kim, Y.C. Park, S.G. Ansari, B.S. Lee and H.S. Shin, Thin Solid Films, 426, 124-131 (2003).

[17] V. Brinzari, I. Damaskin, L. Trakhtenberg, B.K. Cho and G. Korotcenkov, Thin Solid Films, 552, 225-231 (2014).

[18] P.K. Manoj, B. Joseph, V.K. Vaidyan and D. Sumangala Devi Amma, Ceram. Int., 33, 273-278 (2007).

[19] H. El Rhaleb, E. Benamar, M. Rami, J.P. Roger, A. Hakam and A. Ennaoui, Appl. 
Surf. Sci., 201, 138-145 (2002).

[20] E. Benamar, M. Rami, C. Messaoudi, D. Sayah and A. Ennaoui, Sol. Energy Mater. Sol. Cells, 56, 125-139 (1999).

[21] A.R. Babar, S.S. Shinde, A.V. Moholkar, C.H. Bhosale, J.H. Kim and K.Y. Rajpure, J. Alloys Compd., 509, 3108-3115 (2011).

[22] K. Ravichandran and K. Thirumurugan, J. Mater. Sci. Technol., 30, (2) 97-102 (2014).

[23] S. Marikkannu, M. Kashif, N. Sethupathy, V.S. Vidhya, S. Piraman, A. Ayeshamariam, M. Bououdina, N.M. Ahmed and M. Jayachandran, Mater. Sci. Semicond. Process., 27, 562-568 (2014).

[24] Nisha M, Anusha S, Antony A, Manoj R, Jayaraj MK. Appl Surf Sci 2005;252:1430.

[25] Reddy VS, Das K, Dhar A, Ray SK. The effect of substrate temperature on the properties of ITO thin films for OLED applications. Semicond Sci Technol 2006;21:1747.

[26] Akkad FE, Marafi M, Punnoose A, Prabu G. Phys. Status Solidi 2000;177:445.

[27] Wohlmuth W, Adesida I.. Thin Solid Film 2005;479:223.

[28] Po-Shen Shen, Chuan-Ming Tseng, Ta-Chuan Kuo Ching-Kuei Shih, Ming-Hsien Li,Peter Chen, Solar Energy 120 (2015) 345-356

[29] H M Rietveld, J. Appl. Cryst. 2 (1969) 65-71.

[30] Shaaban, E. R., Kansal, I., Mohamed, S., Ferreira, Physica B: Condensed Matter. 404 (2009) 3571.

[31] J. Zhang, L. Feng, W. Cai, J. Zheng, Y. Cai, B. Li, L. Wu, Y. Shao, Thin Solid Films 414 (2002) 113-118.

[32] A. Goktas, F. Aslan, I. H. Mutlu, J Mater Sci: Mater Electron 23 (2012) 605-611

[33] Jaeger, Richard C. (2002). Introduction to Microelectronic Fabrication (2nd ed.). New Jersey: Prentice Hall. pp. 1-88. ISBN $\underline{0-201-44494-1 .}$.

[34] [31] E. R. Shaaban, J. Alloys Compd. 563 (2013) 274.

[35] D. Pereda Cubian, M. Haddad, R. Andre, R. Frey, G. Roosen, J. Arce, C. Diego, L. Flytzains, Physical Review B 67 (2003) 45308. 
[36] M. Emam-Ismail, E.R. Shaaban, M. El-Hagary, I. Shaltout, Philosophical Magazine 90 (2010) 3499.

[37] M. El-Hagary, M. Emam-Ismail, E.R. Shaaban, I. Shaltout, Journal of Alloys and Compounds 485 (2009) 519.

[38] Mansour Mohamed, A. M. Abdelraheem, M. I. AbdElrahman, N. M. A. Hadia, E. R. Shaaban, Applied Physics A (2019) 125:483.

[39] M. Mohamed, E. Shaaban, M.N. Abd-el Salam, A. Abdel-Latief, S.A. Mahmoud, M. Abdel-Rahim, Optik, 178 (2019) 1302-1312.

[40] C. Huang, H. Weng, Y. Jiang, H. Ueng, Vacuum 83 (2009) 313.

[41] E. Bacaksiz, S. Aksu, N. Ozer, M. Tomakin, A. Ozcelik, Applied Surface Science 256 (2009) 1566.

[42] Tauc, J., Radu Grigorovici, and Anina Vancu. physica status solidi (b) 15.2 (1966): 627-637.

[43] T. Mahalingam, V. Dhanasekaran, R. Chandramohan, J.K. Rhee, Journal of Materials Science 47 (2012) 1950.

[44] J. H. Kim, B. D. Ahn, C. H. Lee, K. A. Jeon, H. S. Kang, G. H. Kim and S. Y. Lee, Thin Solid Films 515, 3580 (2007).

[45] A. Elikkottil, M. Tahersima, S. Gu, V. J. Sorger, B. Pesala “A Spectrally-tunable Dielectric Grating based Metasurface for Broadband Planar Light Concentrator" Nature Scientific Reports 9:11723 (2019).

[46] S. Gupta, M. H. Tahersima, V. J. Sorger, B. Pesala, "Silicon nitride grating based planar spectral splitting concentrator for NIR light Harvesting" Optics Express, 28, 15 (2020).

[47] M. H. Tahersima, M. Danang Birowosuto, Z. Ma, W. C. Coley, M. Valentin, I. Lu, K. Liu, Y. Zhou, A. Martinez, et al. "Testbeds for Transition Metal Dichalcogenide Photonics: Efficacy of Light Emission Enhancement in Monomer vs. Dimer Nanoscale Antennas" ACS Photonics 4, 1713-1721 (2017).

[48] M. Tahersima, V. J. Sorger, "Enhanced Photon Absorption in Spiral Nanostructured Solar Cells using layered 2-D Materials" Nanotechnology 26, 344005 (2015).

[49] R. Maiti, C. Patil, T. Xie, J. Ghasemi, M.A.S.R. Saadi, R. Amin, M. Miscuglio, D. Van Thourhout, S.D. Solares, T. Low, R. Agarwal, S. Bank, V. J. Sorger "StrainEngineered Integrated $\mathrm{MoTe}_{2}$ Photodetector for High Responsivity at $1.55 \mu \mathrm{m}$ " 
Nature Photonics 14, 578-484 (2020).

[50] V. J. Sorger, R. Maiti, "Roadmap for Gain-Bandwidth-Product Enhanced Photodetectors" Optical Materials Express, 10(9), 2192-2200 (2020).

[51] Y. Gui, M. Miscuglio, Z. Ma, M. T. Tahersima, V. J. Sorger "Towards integrated metatronics: a holistic approach on precise optical and electrical properties of Indium Tin Oxide“ Nature Scientific Reports 9(1), 1-10 (2019).

[52] Z. Ma, Z. Li, K. Liu, C. Ye, V. J. Sorger "Indium-Tin-Oxide for Highperformance Electro-optic Modulation” Nanophotonics 4, 1 198-213 (2015).

[53] R. Amin, J. B. Khurgin, V. J. Sorger "Waveguide-based electro-absorption modulator performance: comparative analysis" Optics Express 26, 11, 15445-15470 (2018).

[54 ] V. J. Sorger, R. Amin, J. B. Khurgin, Z. Ma, S. Khan "Scaling Vectors for AttoJoule per Bit Modulators” Journal Optics 20, 014012 (2018).

[55] C. Ye, S. Khan, Z.R. Li, E. Simsek, V. J. Sorger “ $\square$-Size ITO and Graphenebased Electro-optic Modulators on SOI" IEEE Selected Topics in Quantum Electronics, 4, 20 (2014).

[56] S. K. Pickus, S. Khan, C. Ye, Z. Li, V. J. Sorger "Silicon Plasmon Modulators: Breaking Photonic Limits" IEEE Photonics Society, 27, 6 (2013).

[57] V. J. Sorger, D. Kimura, R.-M. Ma, X. Zhang "Ultra-compact Silicon nanophotonic Modulator with broadband Response" NANOPHOTONICS 1, 1, 17-22 (2012).

[58] C. Huang, S. Pickus, R. Lamond, Z. Li, et al. "A Sub- $\lambda$ Size Modulator Beyond the Efficiency-Loss Limit” IEEE Photonics Journal 5, 4 (2013).

[59] M. H. Tahersima, Z. Ma, Y. Gui, S. Sun, H. Wang, R. Amin, H. Dalir, R. Chen, M. Miscuglio, V. J. Sorger, "Coupling-enhanced Dual ITO Layer Electro-absorption Modulator in Silicon Photonics”, NANOPHOTONICS 8, 9, (2019).

[60] R. Amin, R. Maiti, C. Carfano, Z. Ma, M.H. Tahersima, Y. Lilach, D. Ratnayake, H. Dalir, V.J. Sorger "0.52 V-mm ITO-based Mach-Zehnder Modulator in Silicon Photonics" APL Photonics 3,12 (2018).

[61] R. Amin, R. Maiti, Y. Gui, C. Suer, M. Miscuglio, E. Heidari, R. T. Chen, H. Dalir, et al. "Broadband Sub- $\lambda$ GHz ITO Plasmonic Mach-Zehnder Modulator on Silicon Photonics" Optica 7, 3, (2020).

[62] R. Amin, R. Maiti, Y. Gui, C. Suer, M. Miscuglio, E. Heidari, J. B. Khurgin, R. T. Chen, H. Dalir, et al. "Heterogeneously Integrated ITO Plasmonic Mach-Zehnder Interferometric Modulator on SOI” arXiv: 12007:5457. 
[63] C. Ye, K. Liu, R. Soref, et al."A Compact Plasmonic MOS-based 2x2 Electrooptic Switch” NANOPHOTONICS 4, 3, 261-268 (2015).

[64] R. Amin, J. George, S. Sun, T. Ferreira de Lima, A. N. Tait, J. Khurgin, et al. "ITO-based Electro-absorption Modulator for Photonic Neural Activation Function" APL Materials 7, 081112 (2019).

[65] M. Miscuglio, X. Ma, T. El-Ghazawi, T. Itoh, A. Alu, et al. "Analog Computing with Metatronic Circuits" arXiv preprint: 2007.05380.

[66] R. Amin, R. Maiti, J. K. George, X. Ma, Z. Ma, H. Dalir, et al. "A lateral MOSCapacitor Enabled ITO Mach- Zehnder Modulator for Beam Steering" Journal Lightwave Technology 38, 2, 282-290 (2019). 


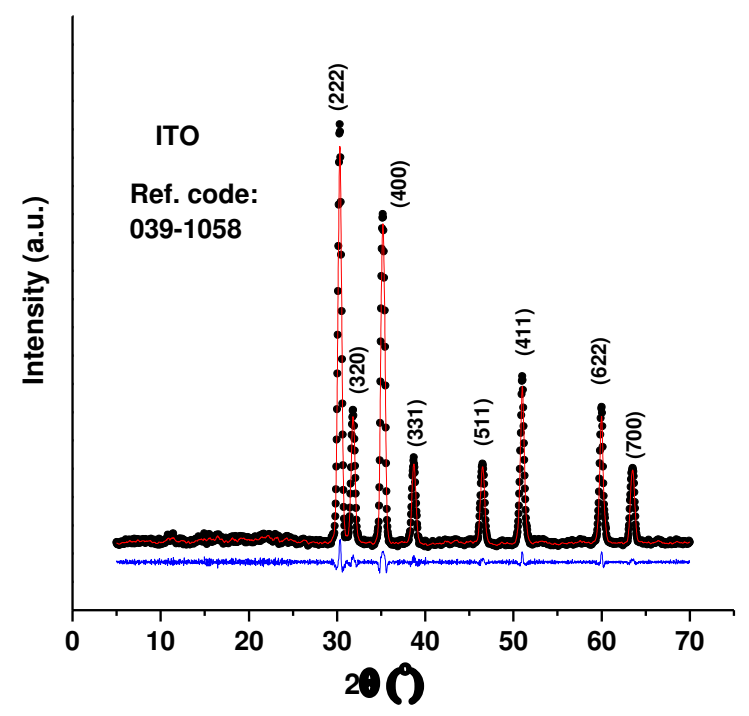

Fig. 1: XRD patterns and Rietveld refinement of polycrystalline ITO powder sample.

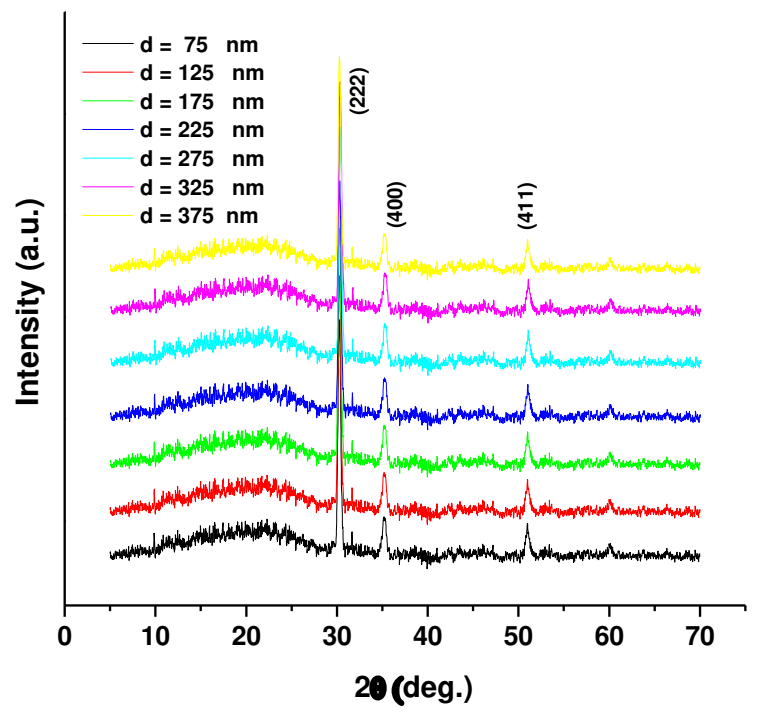

Fig. 2: XRD patterns of the ITO films as a function of different thickness 


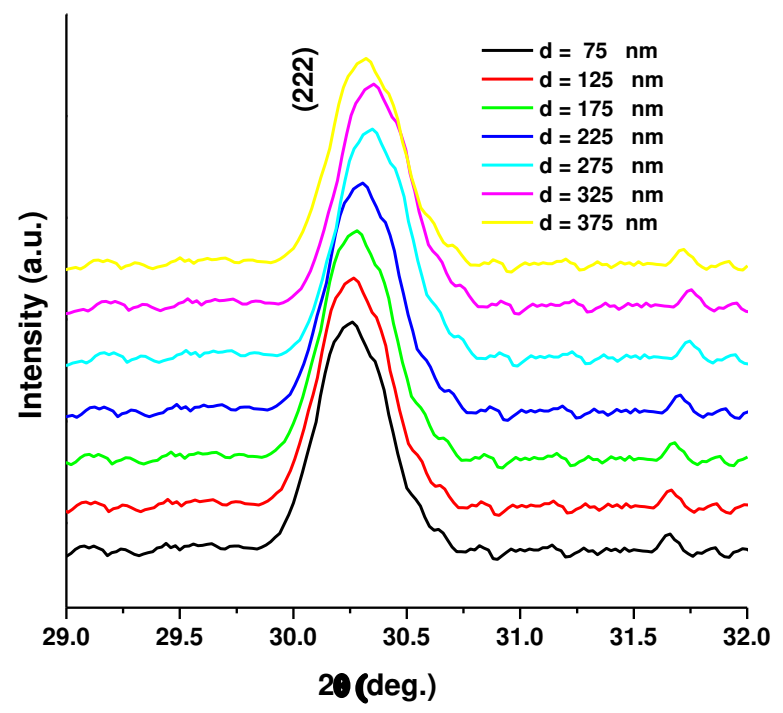

Fig. 3: Amplification of (222) and (400) scattering peaks of ITO a function of different thickness

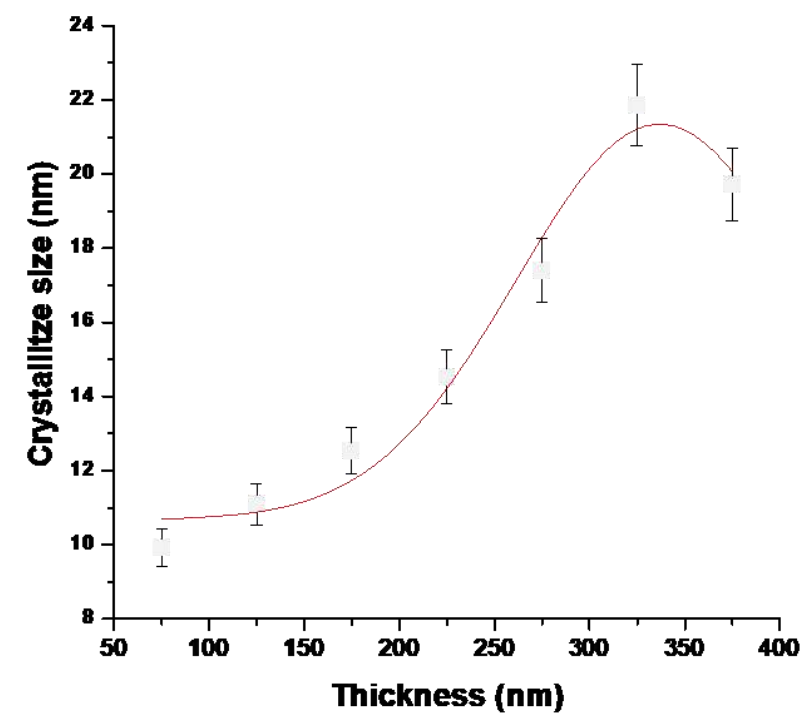

Fig. 4: Crystallize size versus thickness of ITO films 


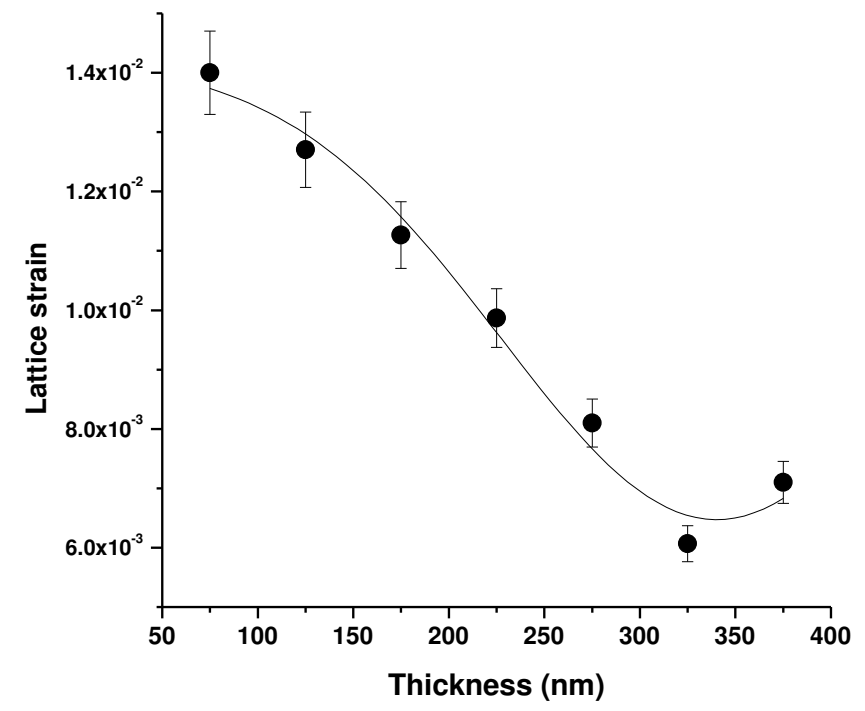

Fig. 5: Lattice strain versus thickness of ITO films
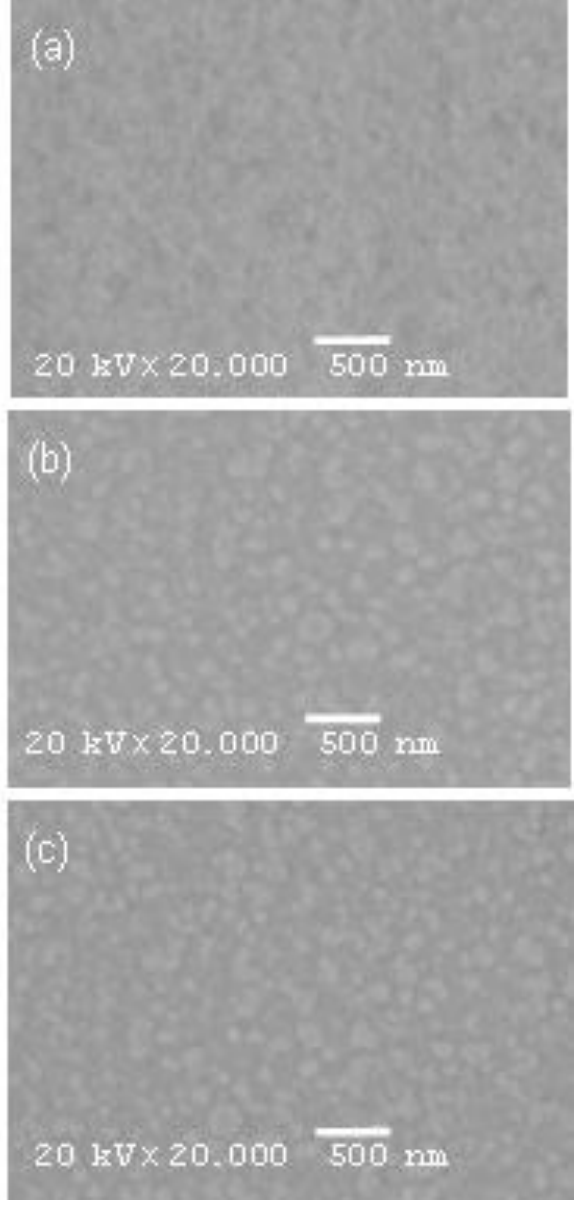

Fig. 6: SEM of three different thickness (a) $d=75 \mathrm{~nm}$, (b) $d=225 \mathrm{~nm}$ and $\mathrm{d}=325 \mathrm{~nm}$. 


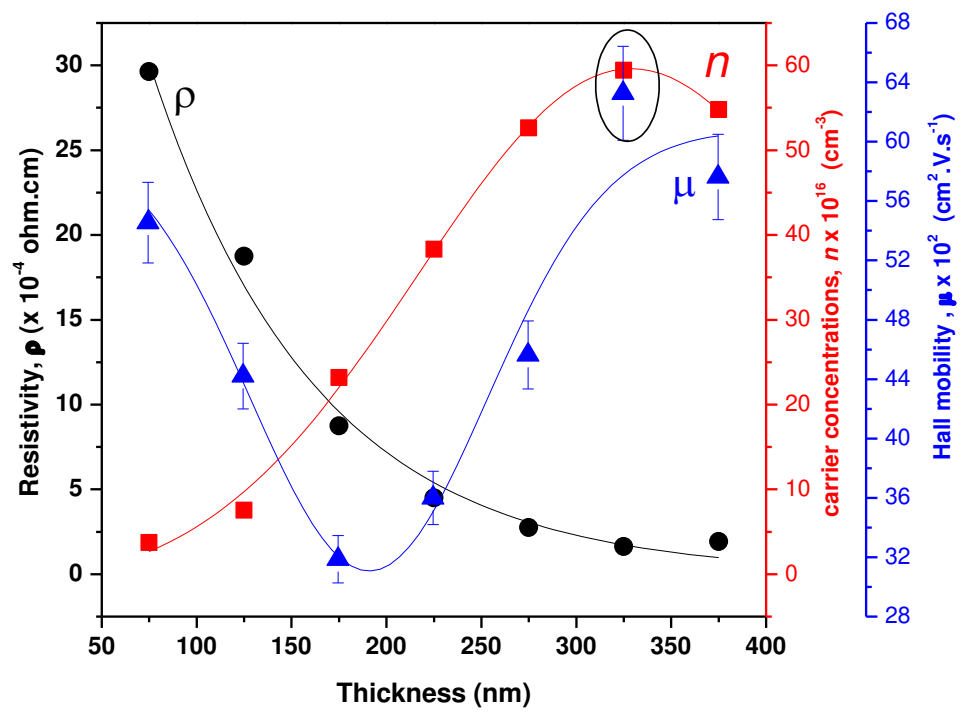

Fig. 7: Electric resistivity versus thickness of ITO thin films

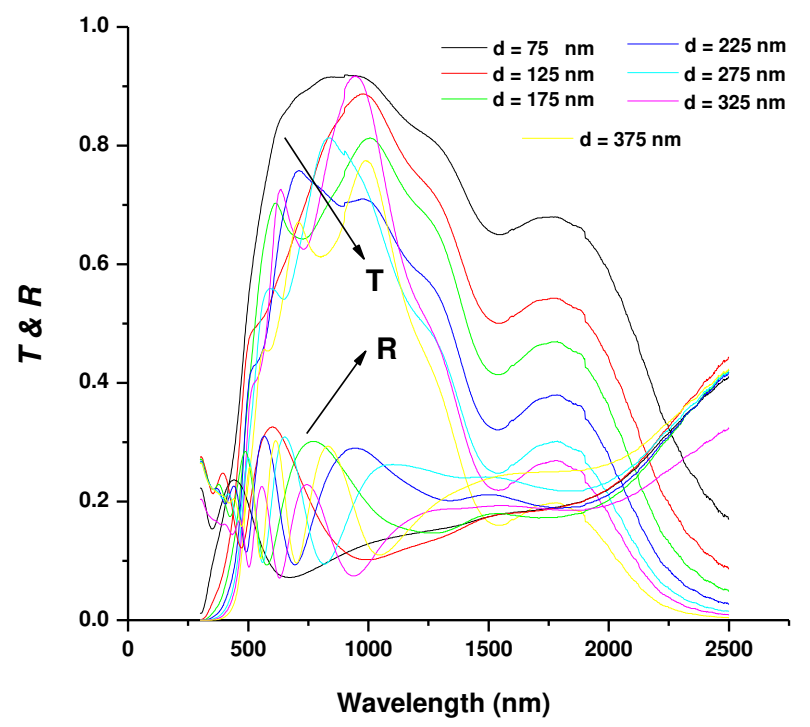

Fig. 8: Experimental transmission and reflection of different thickness of ITO thin films. 
MSE $=2.04$

Roughness $=2.00 \pm 0.46 \mathrm{~nm}$

Thickness \# $1=75.00 \pm 2.61 \mathrm{~nm}$

Angle Offset $=70.000 \pm 1.48$
Roughness $=\underline{2.00 \mathrm{~nm}}$ (fit)

+ Layer \# 1 = B-Spline Thickness \# $1=\underline{75.00 ~ n m ~(f i t) ~}$

+ Substrate $=$ 7059_Cauchy

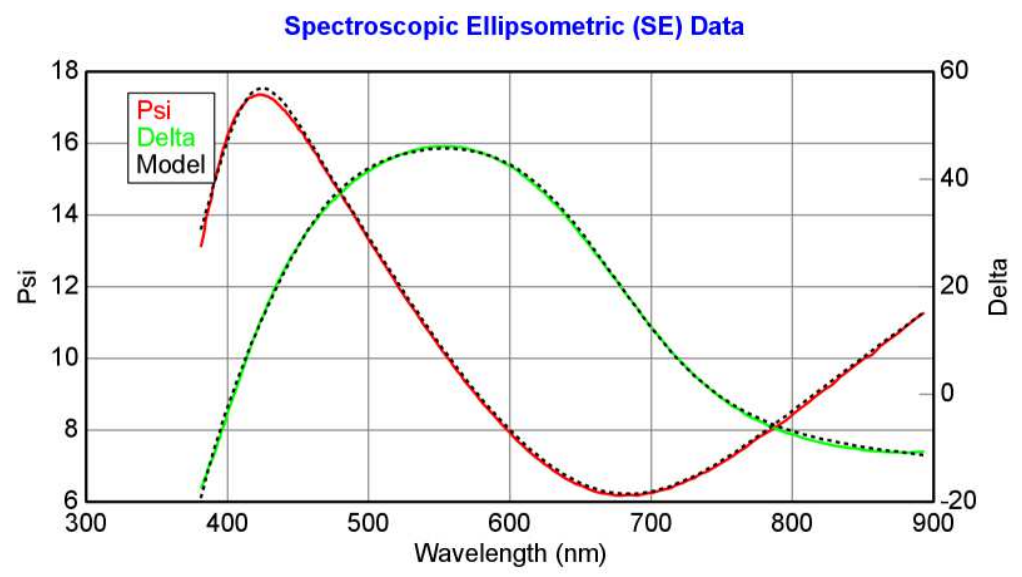

Fig. 9: Experimental and modeled ellipsometric optical parameters Psi and Delta for calculating the film thickness of ITO.

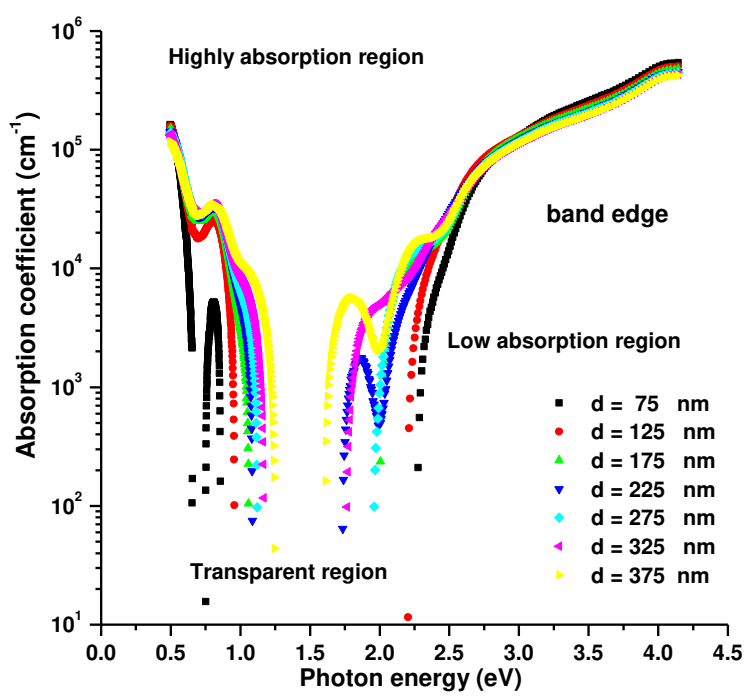

Fig. 10: Absorption coefficient versus photon energy of different thickness of ITO thin films. 


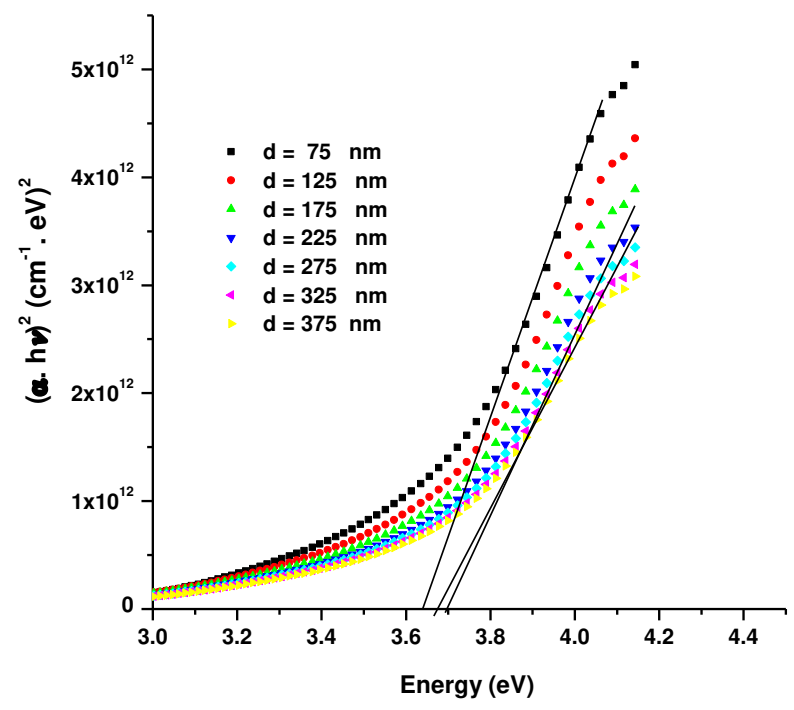

Fig. 11: $(\alpha h v)^{2}$ vs. photon energy $h v$ for of different thickness of ITO thin films.

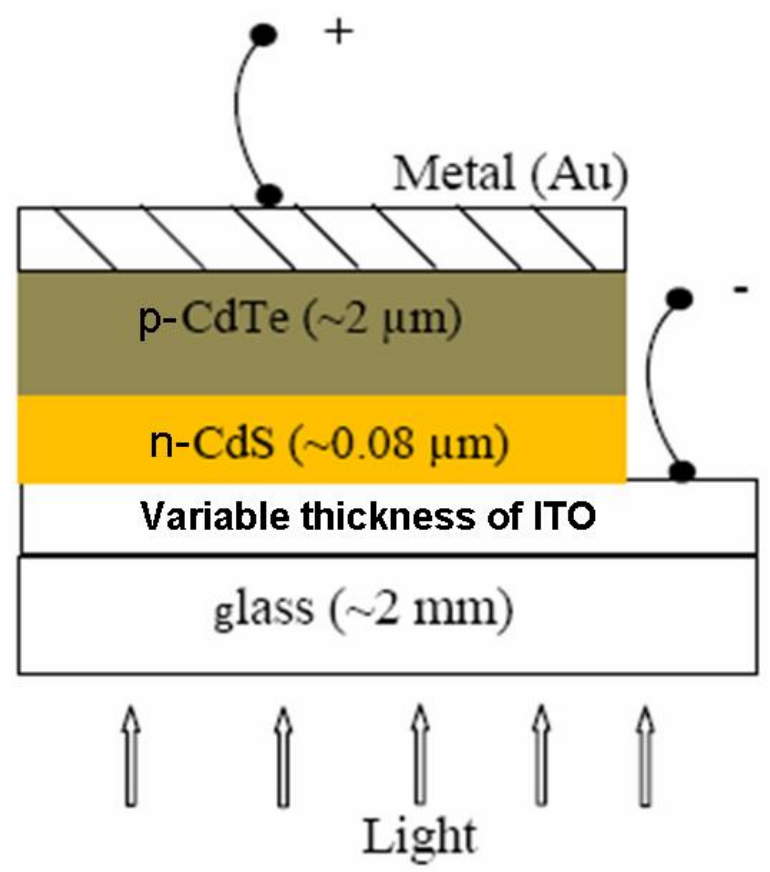

Fig. 12: The basic structure of the glass/ITO/CdS/CdTe/metal thin-film solar cell diagram 

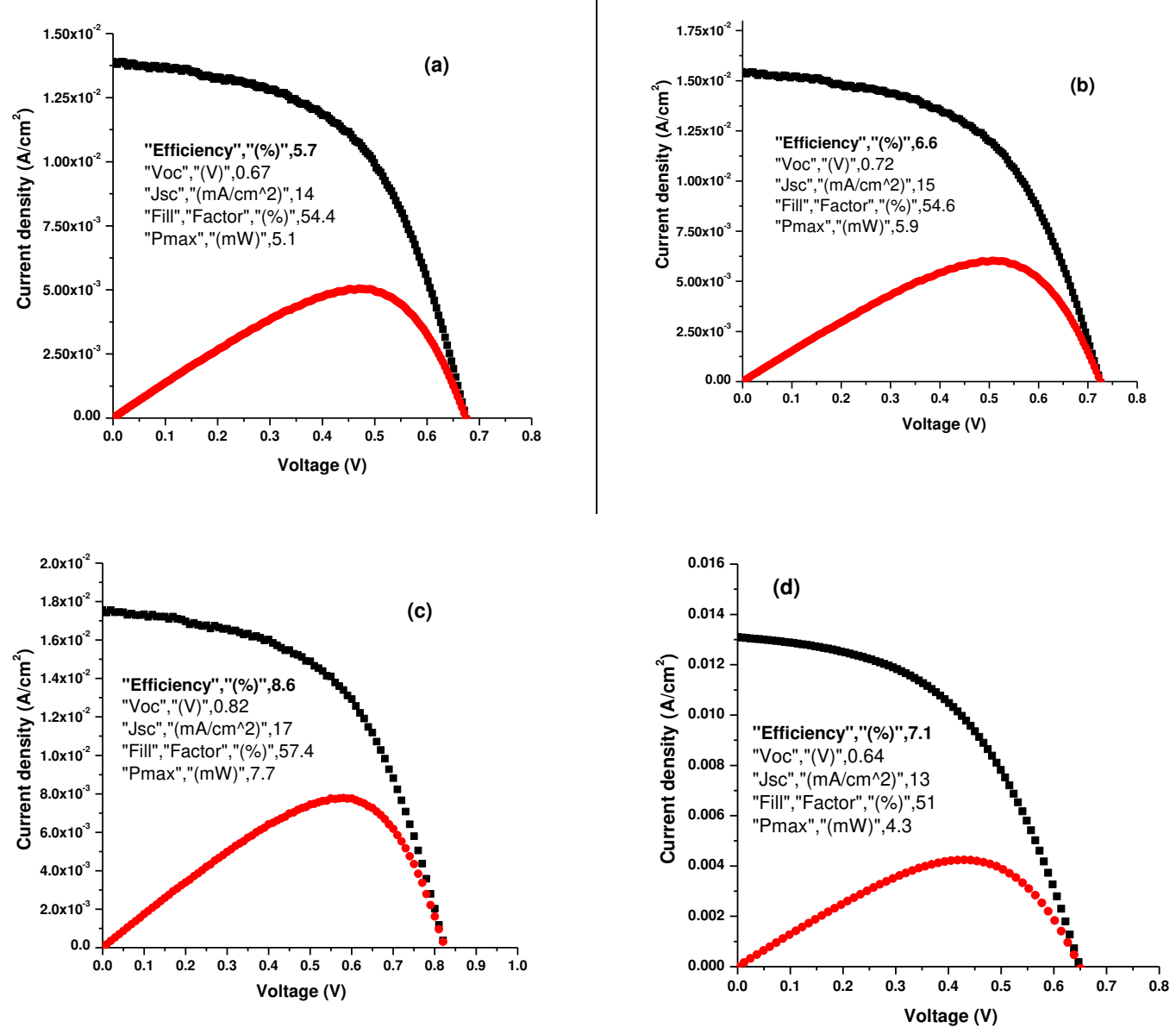

Fig. 13: Characteristic curves of solar cell at (a) $d=75 \mathrm{~nm}$, (b) $d=225 \mathrm{~nm}, d=325$ and $\mathrm{d}=375 \mathrm{~nm}$. 
Table 1: Electrical parameters from Hall measurements of different thickness of ITO

\begin{tabular}{|c|c|c|c|c|c|}
\hline d (nm) & $\begin{array}{l}\rho \times 10^{-4} \\
(\Omega . c m)\end{array}$ & $\begin{array}{c}\sigma \times 10^{3} \\
(\Omega . c m)^{-1}\end{array}$ & $\underset{\left(\mathbf{c m}^{3} \cdot \mathbf{C}^{-1}\right)}{\mathbf{R}_{\mathbf{H}}}$ & $\begin{array}{c}\mathrm{n}_{\mathbf{H}} \times \mathbf{1 0}^{19} \\
\left(\mathrm{~cm}^{-3}\right)\end{array}$ & $\begin{array}{c}\boldsymbol{\mu} \\
\left(\mathrm{cm}^{2} \cdot \mathbf{V} \cdot \mathrm{s}^{-1}\right)\end{array}$ \\
\hline 75 & 29.63 & 0.338 & 0.168 & 3.72 & 56.71 \\
\hline 125 & 18.75 & 0.533 & 0.0829 & 7.54 & 44.21 \\
\hline 175 & 8.75 & 1.143 & 0.0269 & 23.2 & 30.79 \\
\hline 225 & 4.50 & 2.222 & 0.0163 & 38.3 & 36.26 \\
\hline 275 & 2.75 & 3.636 & 0.0119 & 52.6 & 43.21 \\
\hline 325 & 1.63 & 6.154 & 0.0105 & 59.4 & 64.75 \\
\hline 375 & 1.93 & 5.195 & 0.0114 & 54.8 & 59.25 \\
\hline
\end{tabular}


Figures

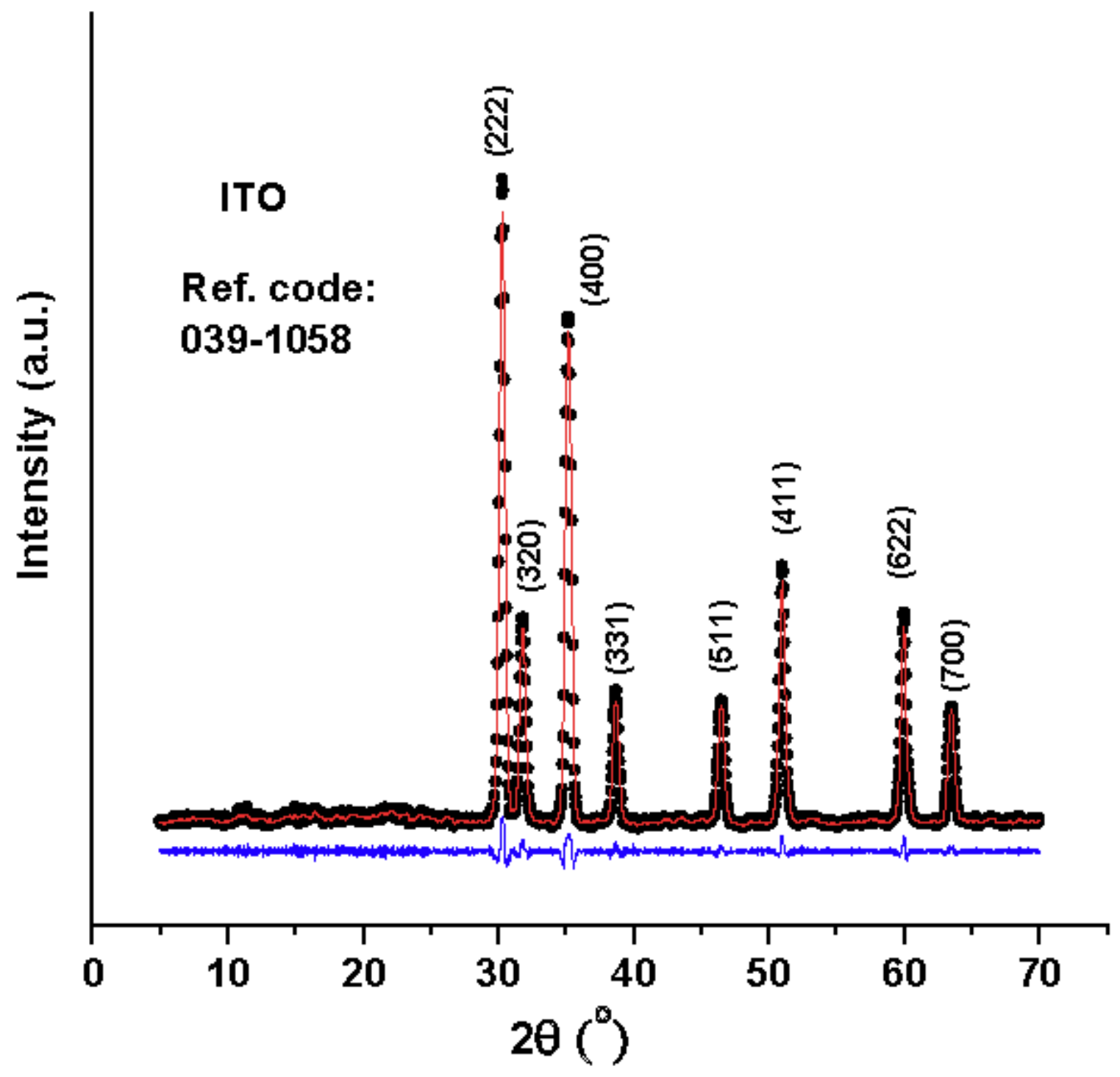

Figure 1

XRD patterns and Rietveld refinement of polycrystalline ITO powder sample. 


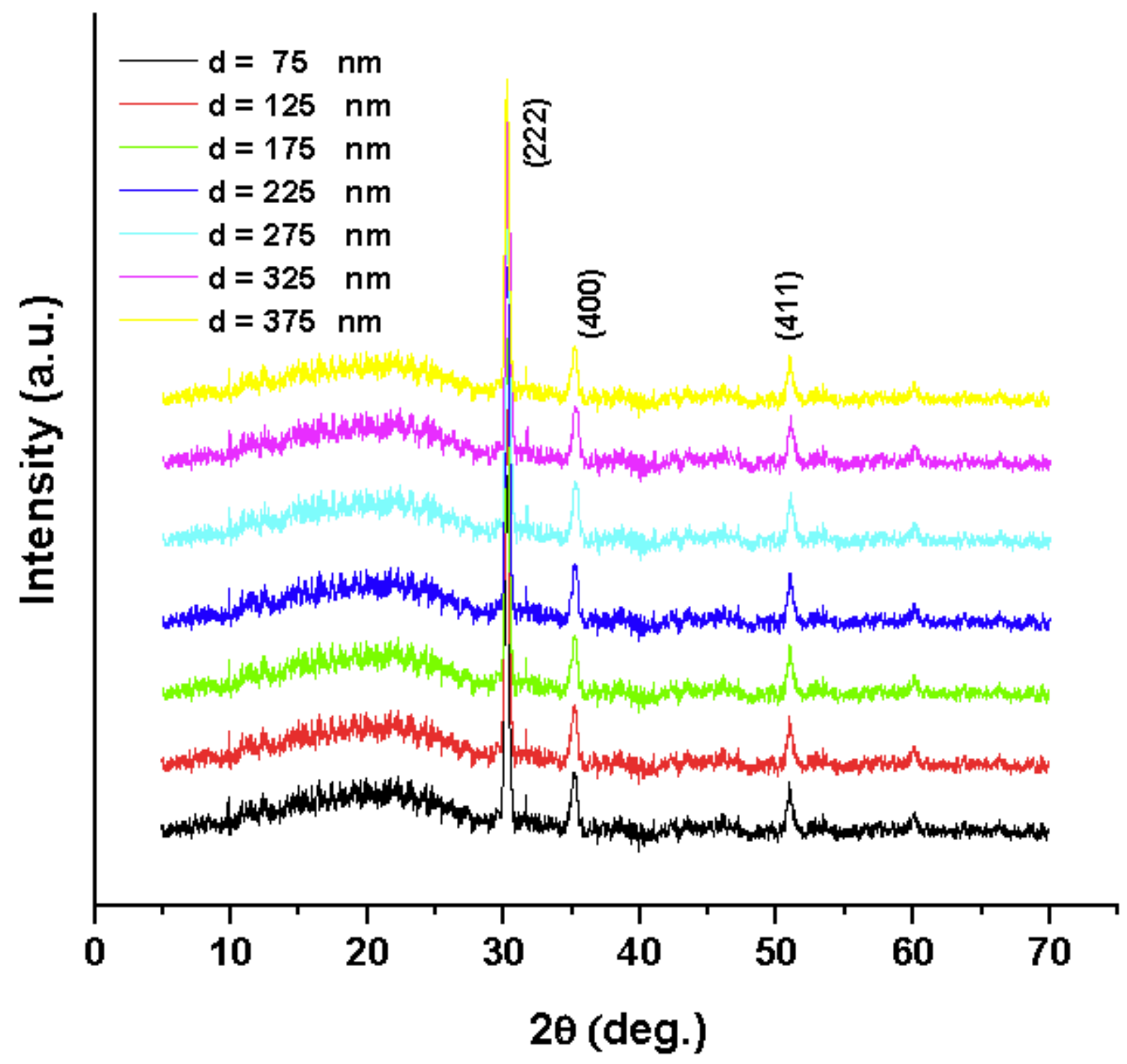

Figure 2

XRD patterns of the ITO films as a function of different thickness 


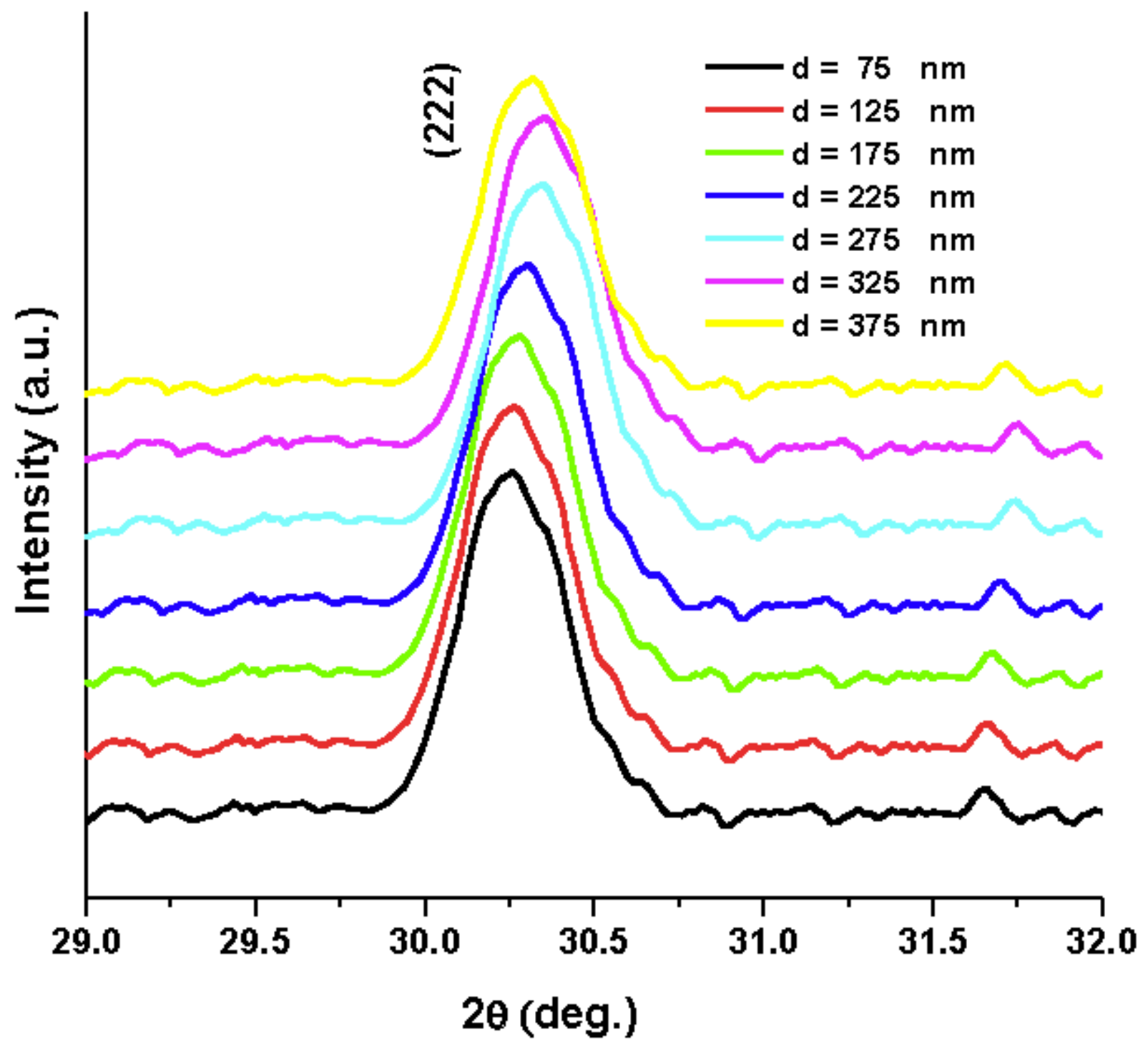

Figure 3

Amplification of (222) and (400) scattering peaks of ITO a function of different thickness 


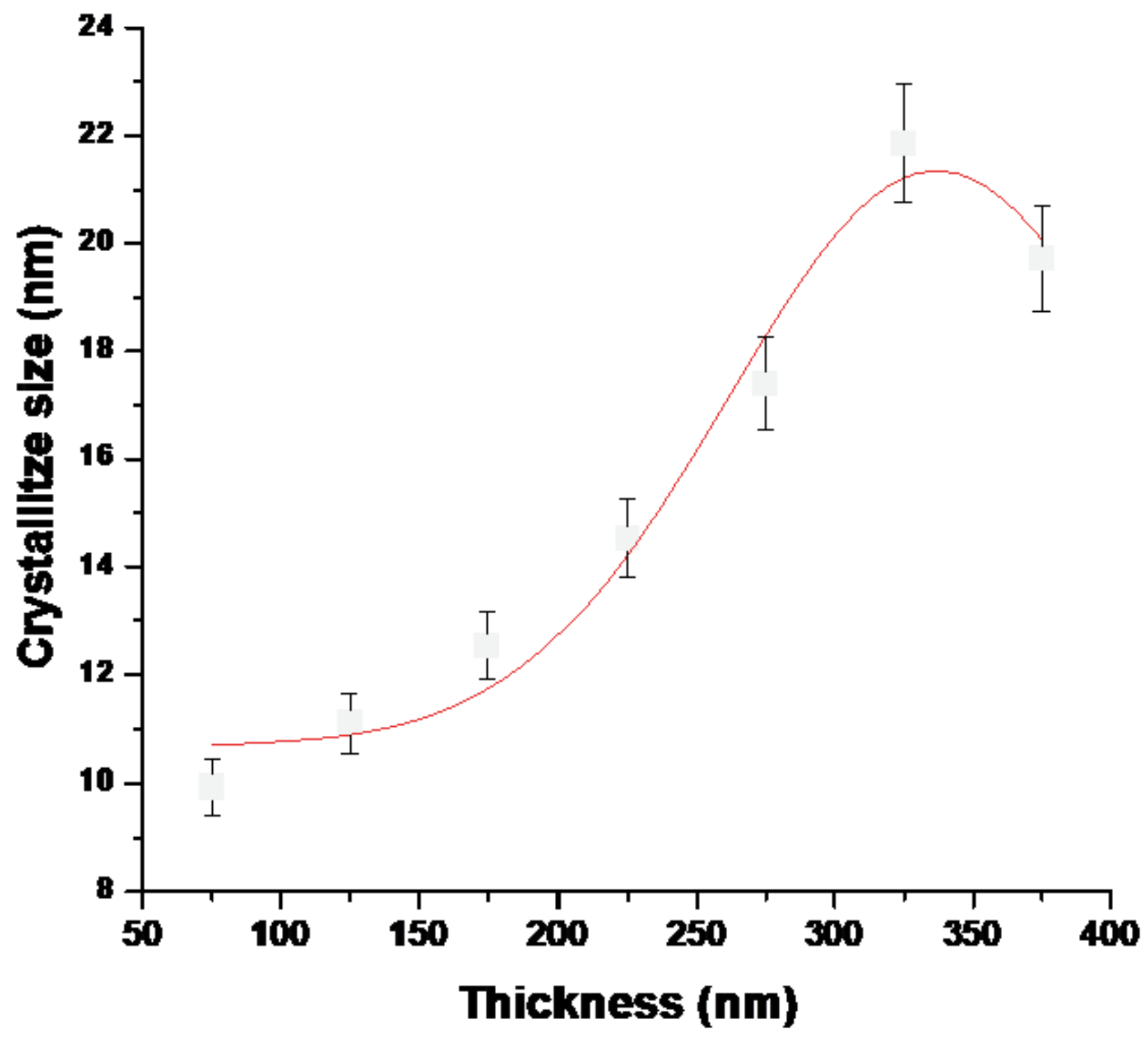

Figure 4

Crystallize size versus thickness of ITO films 


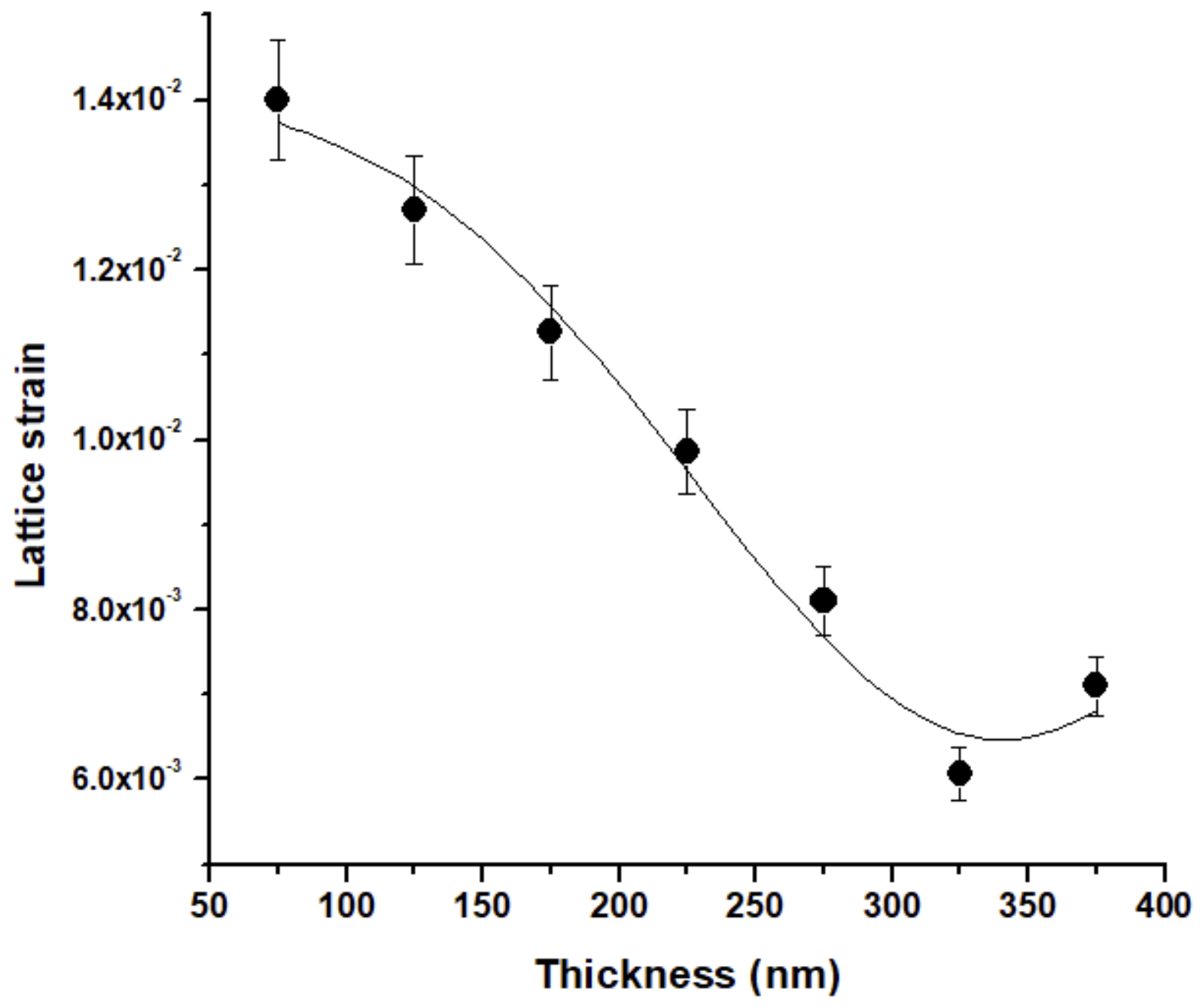

Figure 5

Lattice strain versus thickness of ITO films 

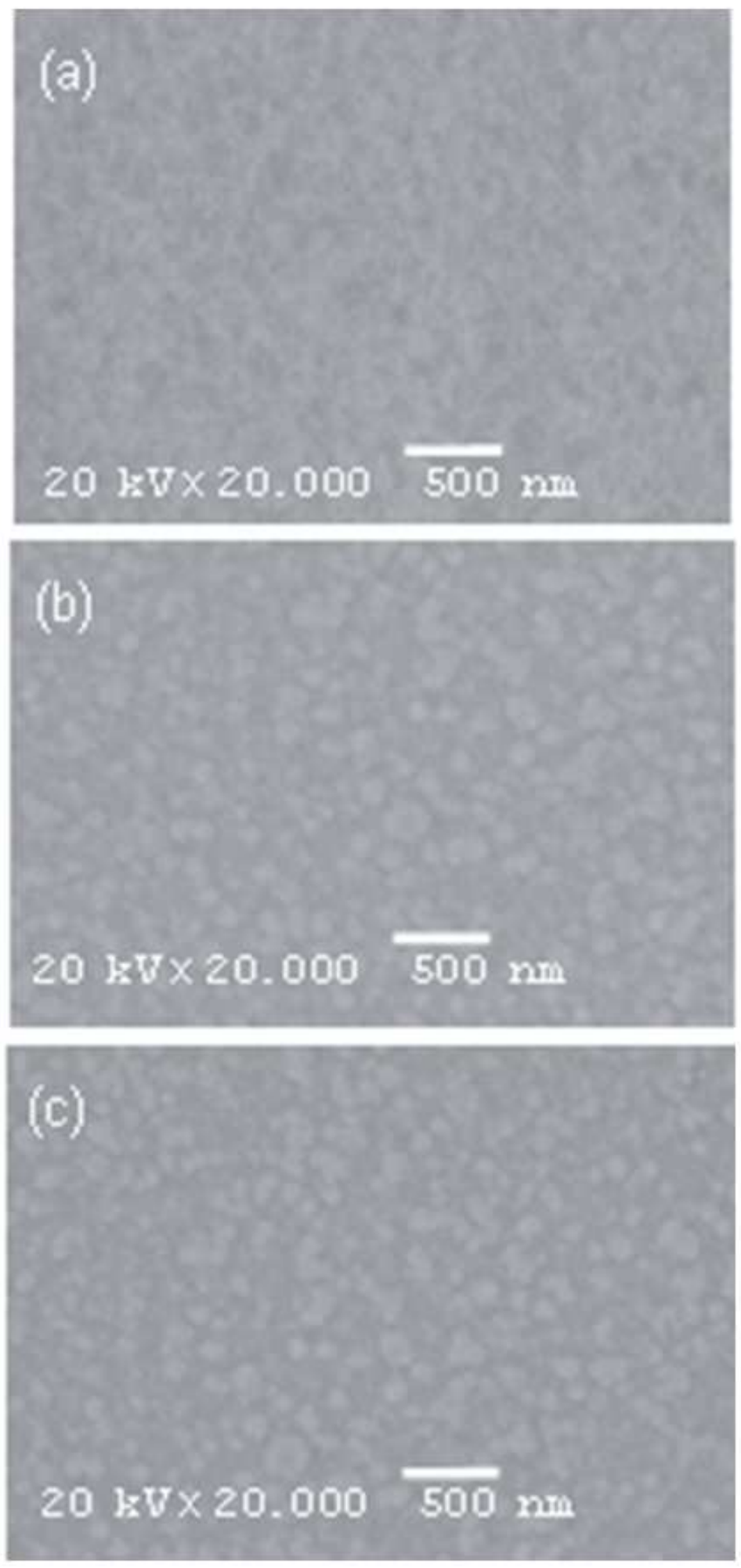

Figure 6

SEM of three different thickness (a) $d=75 \mathrm{~nm}$, (b) $d=225 \mathrm{~nm}$ and $d=325 \mathrm{~nm}$. 


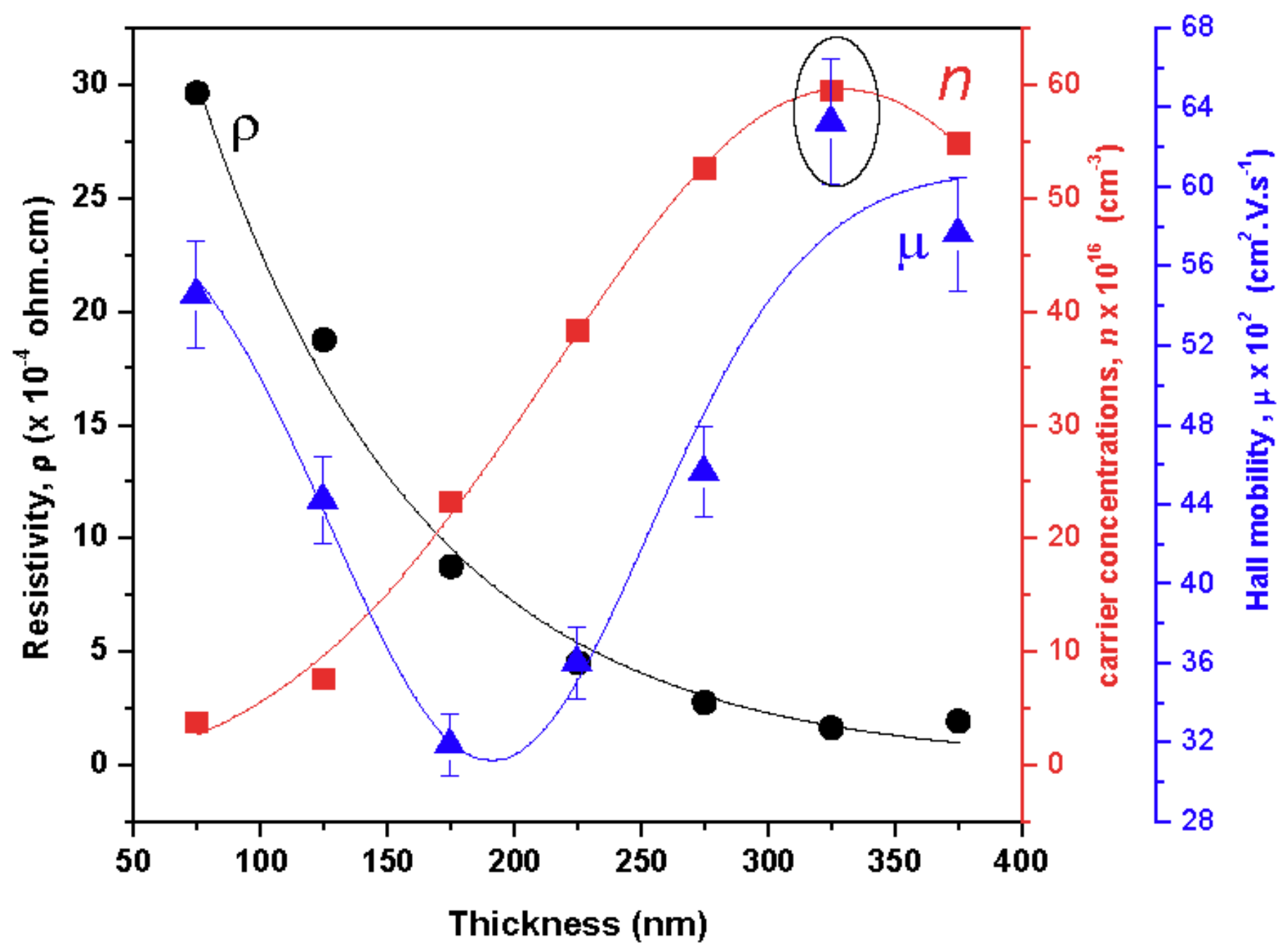

Figure 7

Electric resistivity versus thickness of ITO thin films 


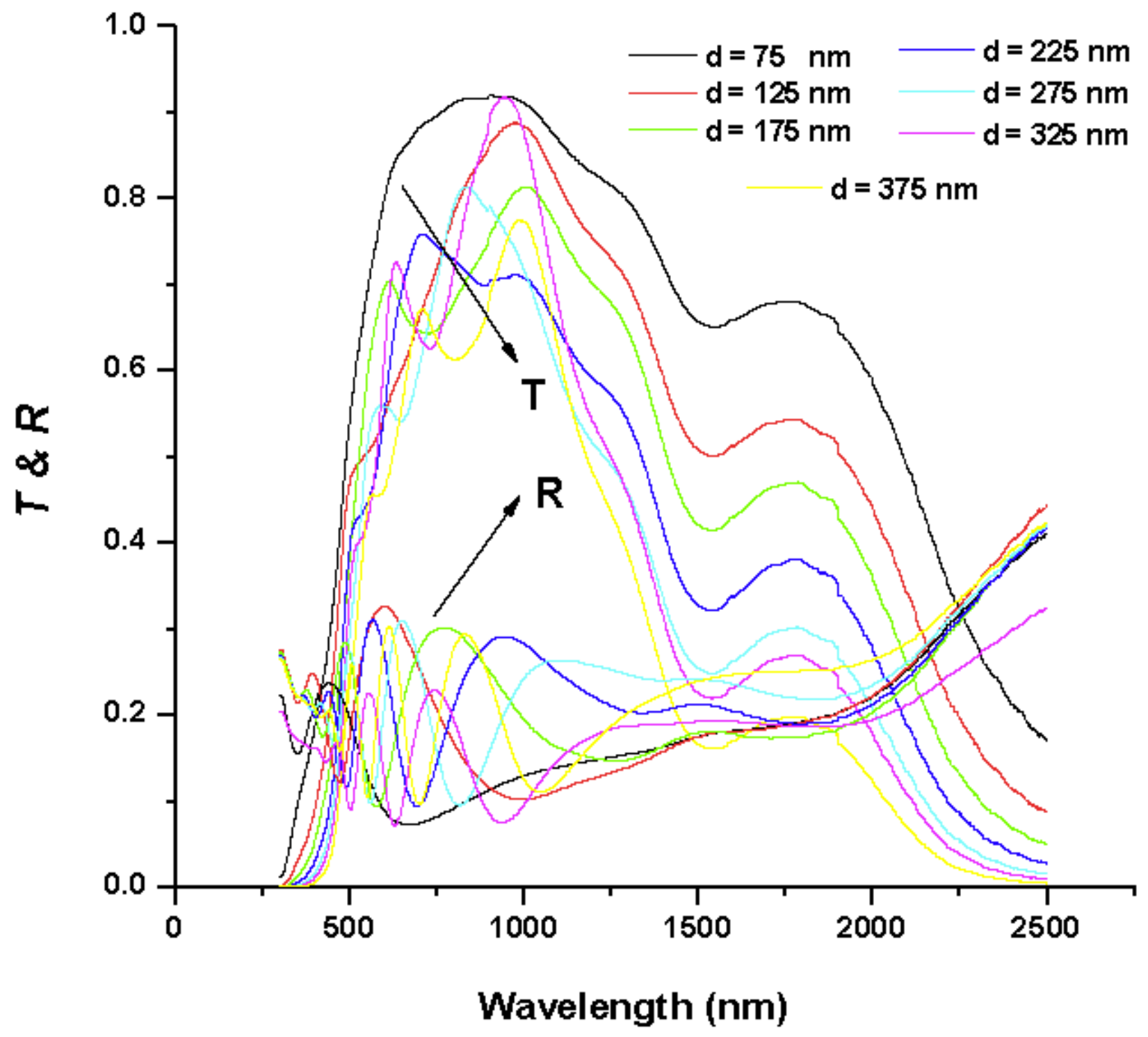

Figure 8

Experimental transmission and reflection of different thickness of ITO thin films. 


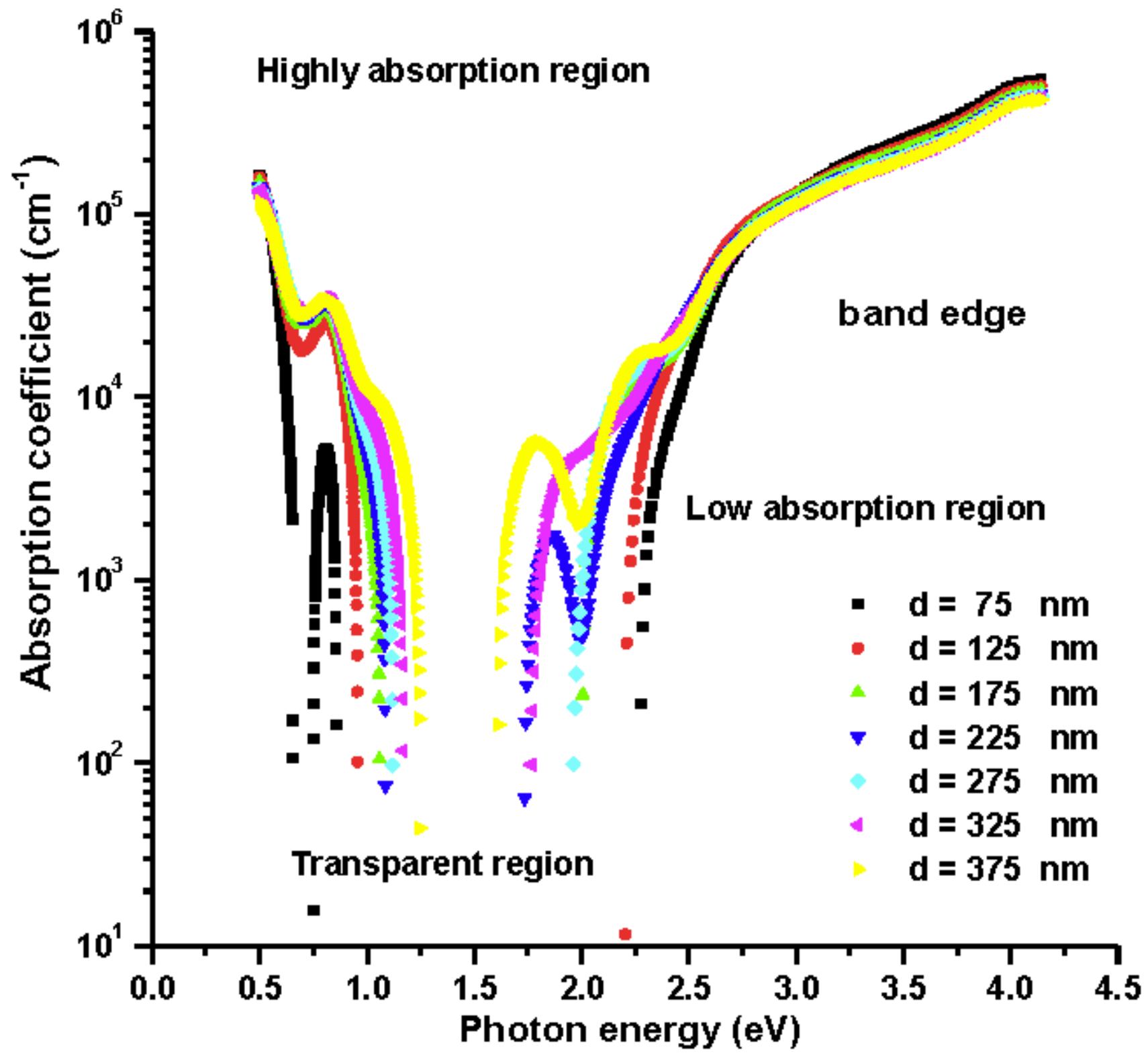

Figure 10

Absorption coefficient versus photon energy of different thickness of ITO thin films. 


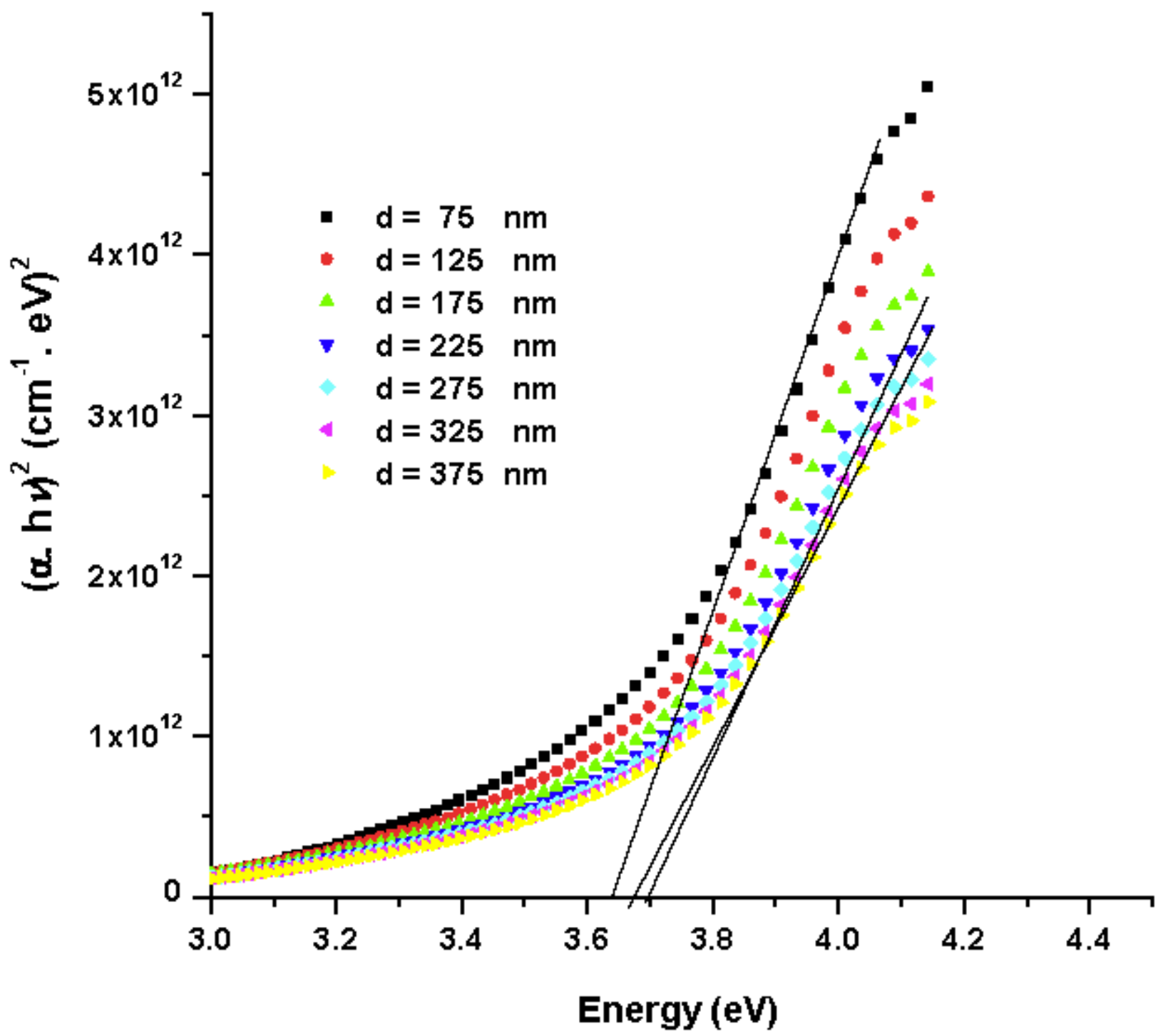

Figure 11

(ahv)2 vs. photon energy hv for of different thickness of ITO thin films. 


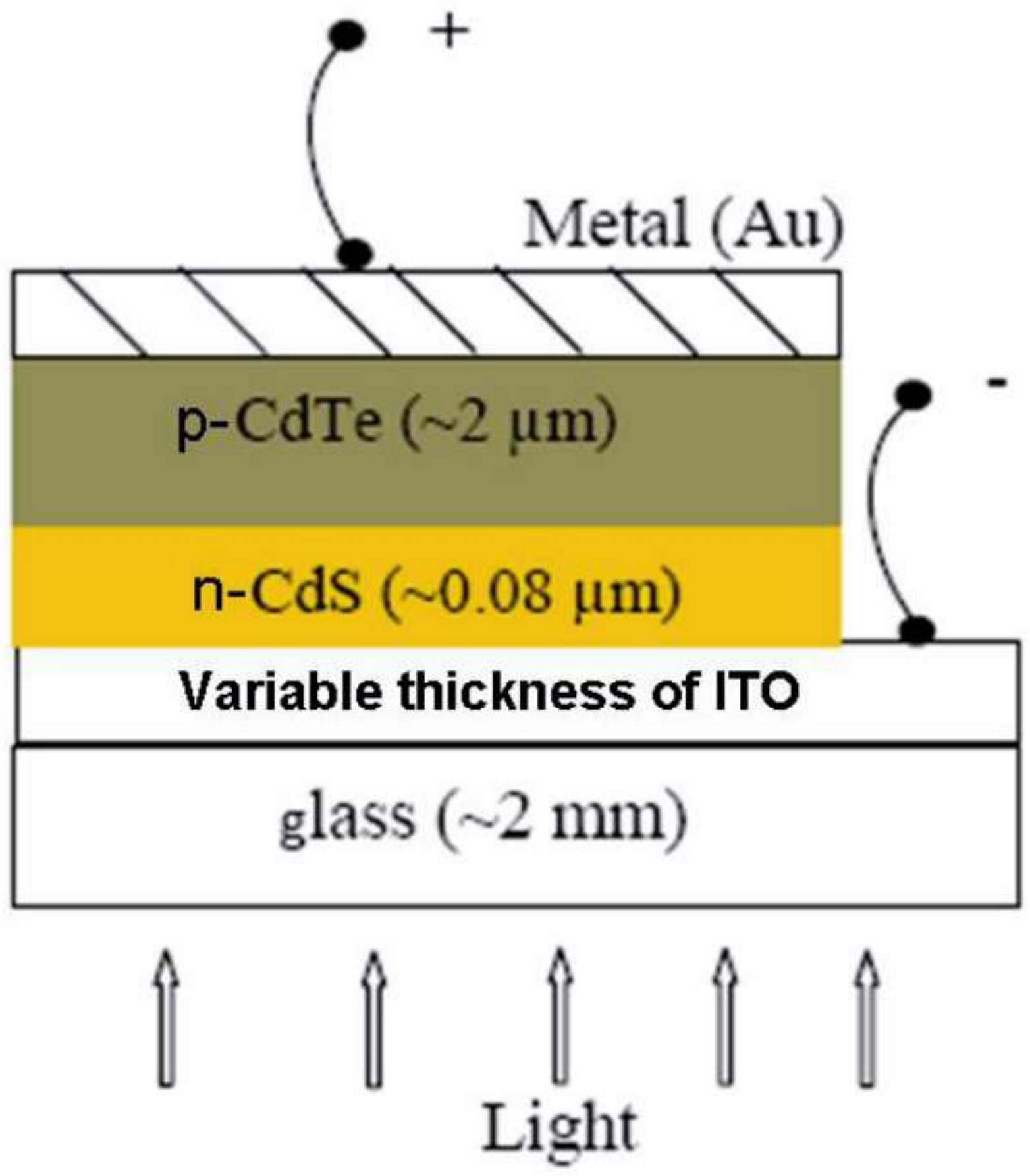

Figure 12

The basic structure of the glass/ITO/CdS/CdTe/metal thin-film solar cell diagram 

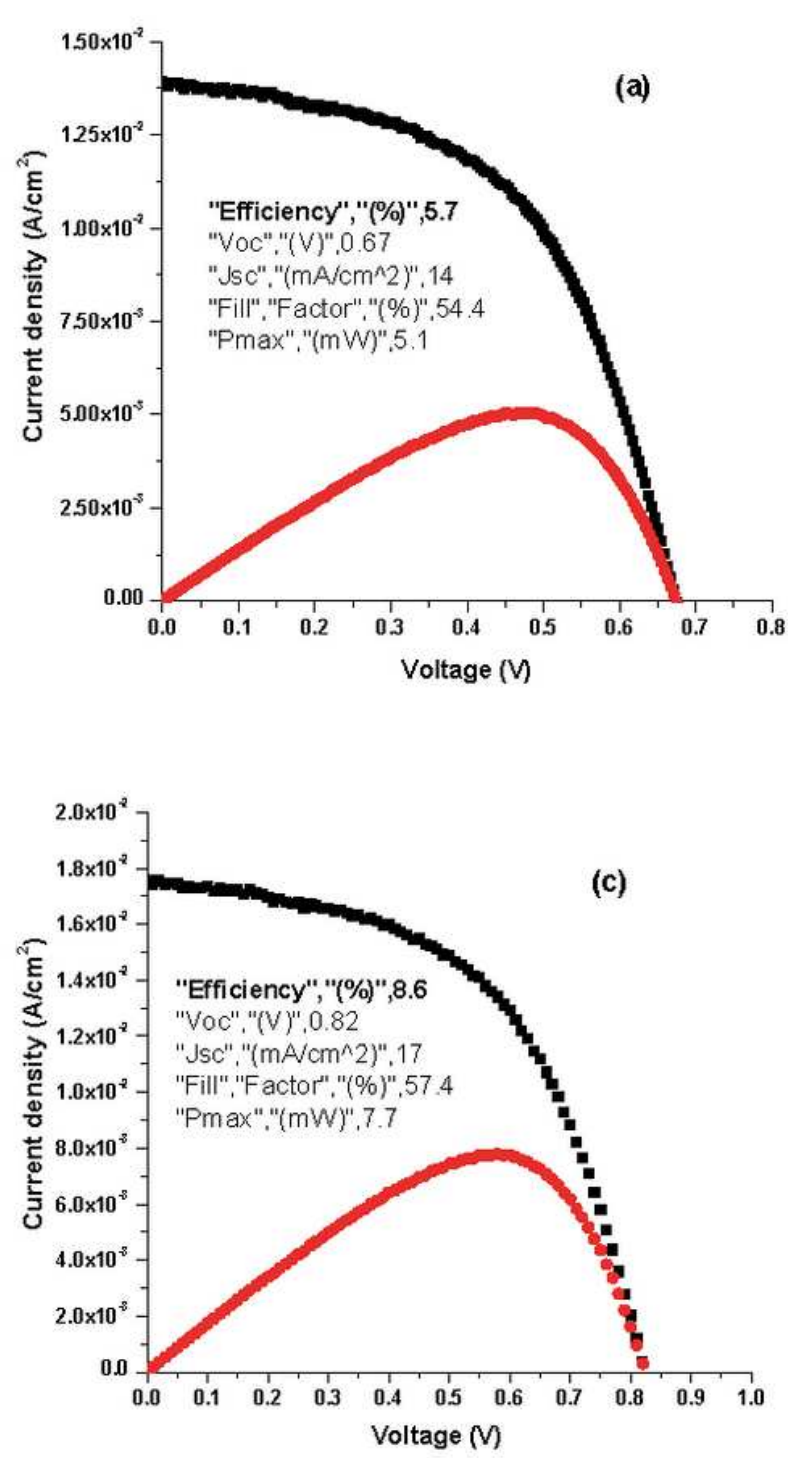
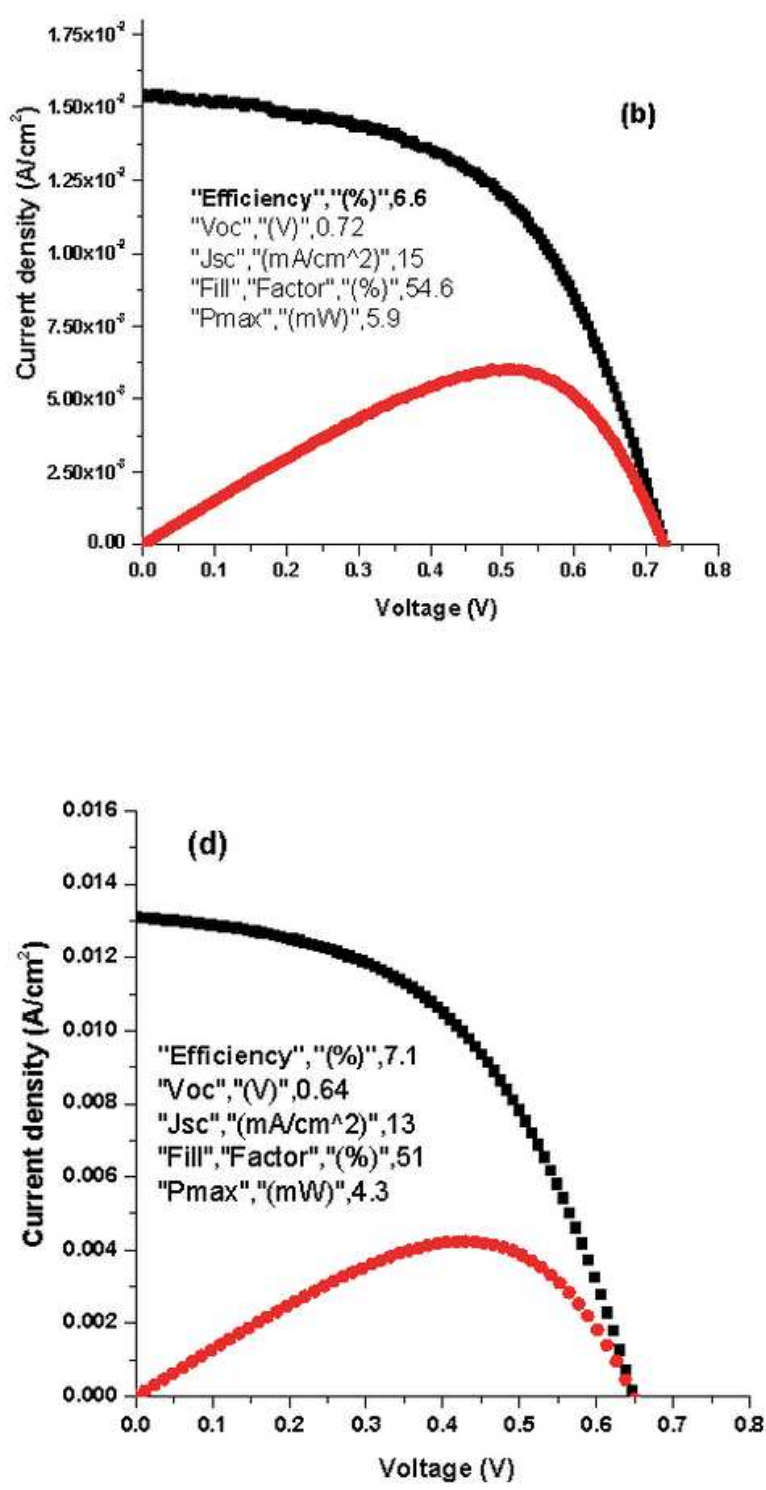

Figure 13

Characteristic curves of solar cell at (a) $d=75 \mathrm{~nm},(b) d=225 \mathrm{~nm}, d=325$ and $d=375 \mathrm{~nm}$. 